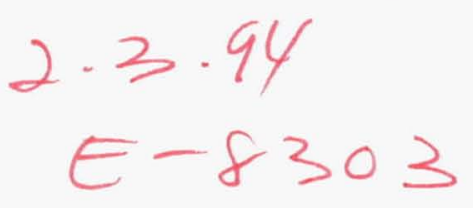

NASA Contractor Report 194442

IEPC-93-194

\title{
Mechanisms of Anode Power Deposition in a Low Pressure Free Burning Arc
}

George C. Soulas

Ohio State University

Columbus, Ohio

and

Roger M. Myers

Sverdrup Technology, Inc.

Lewis Research Center Group

Brook Park, Ohio

Prepared for

Lewis Research Center

Under Contract NAS3-25266

\section{N/SA \\ National Aeronautics and \\ Space Administration}




\title{
Mechanisms of Anode Power Deposition in a Low Pressure Free Burning Arc
}

\author{
George C. Soulas* \\ Ohio State University \\ Columbus, Ohio 43210 \\ Roger M. Myers** \\ Sverdrup Technology, Inc. \\ Lewis Research Center Group \\ Brook Park, Ohio 44142
}

\begin{abstract}
Anode power deposition is a dominant power loss mechanism for arcjets and MPD thrusters. In this study, a free burning arc experiment was operated at pressures and current densities similar to those in arcjets and MPD thrusters in an attempt to identify the physics controlling this loss mechanism. Use of a free burning arc allowed for the isolation of independent variables controlling anode power deposition and provided a convenient and flexible way to cover a broad range of currents, anode surface pressures, and applied magnetic field strengths and orientations using an argon gas. Test results showed that anode power deposition decreased with increasing anode surface pressure up to $6.7 \mathrm{~Pa}(0.05$ torr) and then became insensitive to pressure. Anode power increased with increasing arc current while the electron number density near the anode surface increased linearly. Anode power also increased with increasing applied magnetic field strength due to an increasing anode fall voltage. Applied magnetic field orientation had an effect only at high currents and low anode surface pressures, where anode power decreased when applied field lines intercepted the anode surface. The results demonstrated that anode power deposition was dominated by the current-carrying electrons and that the anode fall voltage was the largest contributor. Furthermore, the results showed that anode power deposition can be reduced by operating at increased anode pressures, reduced arc currents and applied magnetic field strengths, and with magnetic field lines intercepting the anode.
\end{abstract}

Nomenclature

$A_{p} \quad$ probe area, $\mathrm{m}^{2}$

B applied magnetic field strength, $T$

$\mathrm{E}_{1} \quad$ propellant ionization energy, $\mathrm{eV}$

e electron charge, $1.60 \times 10^{-19} \mathrm{C}$

$\mathrm{J}_{\mathrm{a}} \quad$ anode current, $\mathrm{A}$

$\mathrm{J}_{\text {arc }}$ arc current, $\mathrm{A}$

$\mathrm{J}_{\mathrm{e}} \quad$ electron current, $\mathrm{A}$

$\mathrm{J}_{e}{ }^{\text {emit }}$ electron thermionic emission current from the anode, A

$\mathrm{J}_{\text {csal }} \quad$ electron saturation current, $\mathrm{A}$

$\mathrm{J}_{\mathrm{i}} \quad$ ion current, $\mathrm{A}$

$\mathrm{J}_{\text {isal }} \quad$ ion saturation current, $\mathrm{A}$

$\mathrm{J}_{\mathrm{p}} \quad$ probe current, $\mathrm{A}$

$\mathrm{k} \quad$ Boltzmann's constant, $1.38 \times 10^{-23} \mathrm{~J} / \mathrm{K}$

\footnotetext{
Graduate Student. Currently at

Sverdrup Technology, Inc.

NASA LeRC Group

"Propulsion Engineer, Member AIAA
}

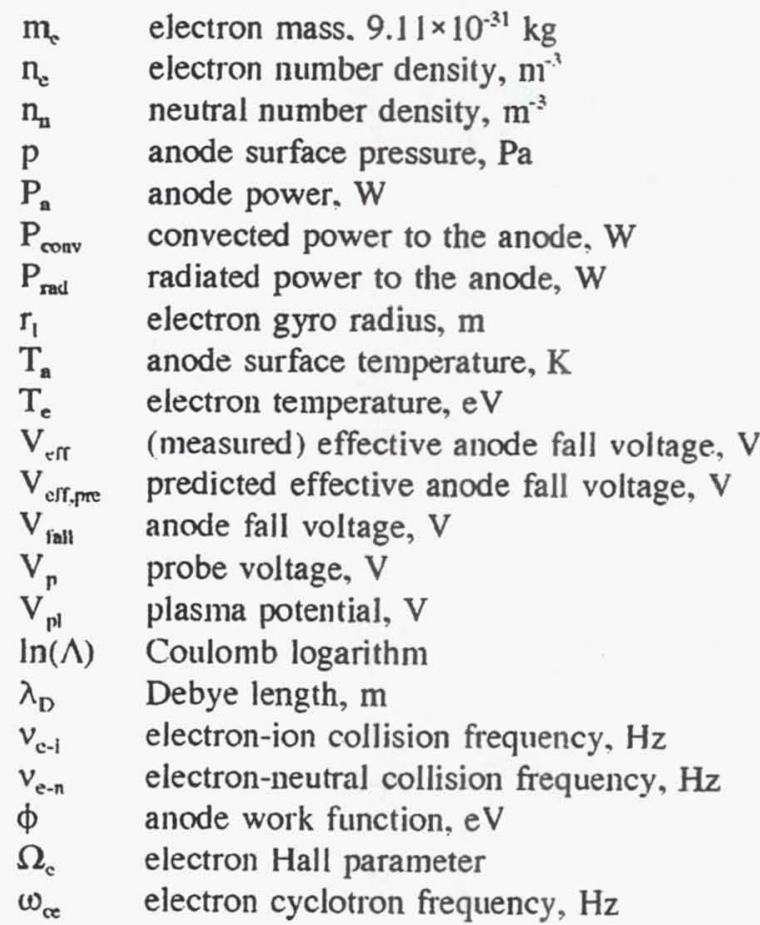




\section{Introduction}

Anode power deposition is currently a dominant power loss mechanism for high performance electric propulsion devices. Thermal arcjets and steady-state magnetoplasmadynamic (MPD) accelerators, which pass a discharge current through the propellant plasma to heat and accelerate the gas, deposit between $15 \%$ and $80 \%$ of the input power into the anode. Not only is this a severe performance penalty, but it introduces thermal design problems since the heat must be radiated from the thruster.

Typical arcjet and MPD thruster designs are shown in Figure 1. Anode power-to-input power percentages (anode power fractions) are currently 15$20 \%$ for arcjets operating at $1 \mathrm{~kW}^{1}$ and $\geq 50 \%$ for steady-state MPD thrusters. ${ }^{2}$ Arcjets are presently baselined for station-keeping applications on geosynchronous communication satellites because their high exhaust velocities permit large fuel savings. MPD thrusters are currently being studied for higher power applications, including orbit raising and planetary missions. These missions require input power-tothrust power conversion efficiencies (thrust efficiencies) between 0.4 and $0.6,{ }^{3}$ which, given the presence of other loss mechanisms, requires that the anode power loss be less than $20 \%$. However, steady-state, 50-200 kW MPD thrusters presently suffer anode power losses between $50 \%$ and $80 \%$ of the thruster input power. ${ }^{2}$ The resulting performance is poor, with exhaust velocities and efficiencies ranging from 8000 to $37000 \mathrm{~m} / \mathrm{sec}$ and 0.10 to 0.23 , respectively. ${ }^{2}$

In an attempt to make MPD thrusters a viable option for space applications, several research efforts were conducted to identify operating conditions that reduce anode power deposition for these devices. ${ }^{2,4-15}$ These efforts included calorimetric measurements of anode power and plasma diagnostics near the anode surface. However, many of these earlier studies were conducted in vacuum facilities with background pressures above $0.12 \mathrm{~Pa}\left(9 \times 10^{-4}\right.$ torr), ${ }^{4-8}$ a regime that significantly influences anode power deposition. ${ }^{2}$ Myers, Kelly, and Jahn, ${ }^{9}$ using thrusters similar to those shown in Figure 1, demonstrated that anode power deposition was the largest contributor to the poor efficiencies of steady-state MPD thrusters. This effort, along with subsequent work, ${ }^{2}$ indicated that anode power losses decreased with increasing propellant flow rate and increasing anode radius. Other research efforts ${ }^{10,11}$ with steadystate MPD thrusters confirmed these trends and also found that although anode power increased mono- tonically with applied magnetic field strength and discharge current, the anode power fraction decreased. Work on pulsed MPD thrusters confirmed that the anode power fraction decreased with increasing input power. ${ }^{12-14}$ However, the lowest steady-state anode power fractions recorded were above $45 \%$, well over that required for steady-state MPD thruster missions.

The failure to reach the required low anode power fractions led to studies directed at identifying the relevant physics..$^{5-14,16}$ In general, the power deposited to the anode of an arc can be expressed as: ${ }^{17}$

$$
\begin{aligned}
P_{a}= & J_{e}\left(\frac{5 k T_{e}}{2 e}+V_{\text {fall }}+\phi\right)-J_{e}^{e m i t}\left(\phi+\frac{5 k T_{e}}{2 e}\right) \\
& +J_{i}\left(E_{i}-\phi\right)+P_{\text {rod }}+P_{c o n v^{\circ}}
\end{aligned}
$$

The first term is the energy transferred to the anode by the current-carrying electrons in the arc column. It includes contributions from the thermal energy of the electrons in the arc column, the energy gained by the electrons accelerating through the anode fall voltage, and the energy that is released when the electron falls through the potential well at the anode surface, respectively. The potential distribution and heat transfer mechanisms at the anode are illustrated in Figure 2. The second term is the thermionically emitted electron current from the anode and includes contributions from the anode work function and the electron thermal energy. Thermionic emission, of course, only occurs for plasma potentials greater than the anode potential. The third term is the energy transferred to the anode by the current-carrying ions. It includes contributions from the ionization potential and internal energy states of the propellant and the anode work function. The final terms are the radiative energy transferred from the plasma and cathode to the anode surface, and the convective energy transferred from the plasma to the anode surface. Past studies on MPD thruster anode power deposition assumed that contributions from anode thermionic electron emission and ion current were negligible..$^{6-9,11-}$ $14,16,18$ The most recent work on steady-state MPD thrusters ${ }^{16}$ indicated that the largest contributor to anode power deposition was from the current-carrying electrons, contributing up to $65-95 \%$ of total anode power, while radiative and convective terms contributed only $5-35 \%$ and less than $5 \%$, respectively. However, in that work there were no direct measurements of the local electron temperatures or the anode 
fall voltage, and magnetic fields were applied throughout the entire effort, which precluded a clear identification of applied magnetic field effects. The only effort that included measurements of electron temperatures at the anode of a steady-state MPD thruster estimated the anode fall voltage using a measured floating potential corrected with a measured electron temperature, ${ }^{9}$ and did not examine applied magnetic field effects. While there has been a considerable amount of work on pulsed MPD thrusters, ${ }^{12-14,18}$ all of these efforts were conducted at anode power densities considerably higher than those considered feasible for practical application. Furthermore, none of these efforts examined applied magnetic field effects and anode fall voltages were estimated using a corrected floating potential. The lack of direct measurements of the anode fall voltages, electron temperatures, and applied magnetic field effects has prevented a complete understanding of the relevant physics involved in anode power deposition.

This study utilized a free burning arc to simulate anode power deposition in MPD thrusters in order to identify the controlling physics and establish techniques for reducing this power loss. Use of a free burning arc permitted the isolation of several of the independent variables controlling anode power deposition and provided a convenient and flexible way to cover a broad parameter space. It did preclude, however, a direct transfer of the results to these propulsion devices since there was no gas acceleration and therefore no simulation of thruster convective heat transfer. Since the majority of anode power is from the current-carrying electrons, current densities and pressures were scaled to match those measured in steady-state MPD thrusters and were varied to determine their effect on anode power deposition. For typical operating conditions, $100 \mathrm{~kW}$ class MPD thrusters have maximum current densities near 11 $\mathrm{A} / \mathrm{cm}^{2} .{ }^{11}$ The anode surface pressure has been measured for a steady-state MPD thruster operating at 30$50 \mathrm{~kW}$ and was found to vary between 4 and $67 \mathrm{~Pa}$ $(0.03 \text { and } 0.50 \text { torr })^{16}$. While several previous anode power deposition studies have used free burning arcs, ${ }^{19-25}$ none have been conducted at these low pressures and current densities. In addition, past free burning arc studies have not examined the effects of applied magnetic fields, which are included in this work. Results from this effort are potentially applicable to arcjets because within the nozzle of an arcjet. where $62-75 \%$ of the total current attaches, ${ }^{26}$ pressures are comparable to those at the anode of a $100 \mathrm{~kW}$ class MPD thruster. ${ }^{16,26}$
The test hardware and vacuum facility are initially described in this paper. This includes a description of the electrodes, electromagnets, pumping facility, diagnostics, procedures, and operating conditions. This is followed by a presentation of the effects of anode surface pressure, arc current, and applied magnetic field strength and orientation on anode power deposition. Throughout this presentation, the results are interpreted within the context of the anode power deposition model as given by Equation 1. A summary of the major conclusions is given at the end of the paper.

\section{Experimental Apparatus}

\section{Test Hardware and Facility}

The test hardware, shown in Figure 3, included the anode, a hollow cathode, and two electromagnets used to apply magnetic fields to the plasma at the anode surface. The anode surface was $2.5 \mathrm{~cm}$ axially downstream from, and $4.4 \mathrm{~cm}$ radially to the side of, the cathode. This arrangement was chosen prevent sprayed hollow cathode material from reaching the anode and changing the surface work function. Ceramic insulator plates were placed behind and in front of the cathode, behind the anode surface, and between the electromagnets and anode to prevent the plasma from directly heating any insulated cables.

The design of the anode and water cooling assembly is shown in Figure 4. The anode was in the shape of a plug, with an exposed planar surface diameter of $0.95 \mathrm{~cm}$. It was inserted into a water cooled, copper anode holder and was held in place with a set screw, allowing the anode to be easily replaced. A graphite foil gasket was inserted between the anode and the copper holder to ensure a uniform electrical contact. Boron nitride was used to thermally and electrically insulate the sides of the anode and the water cooling assembly from the plasma.

The hollow cathode was identical to those used for the discharge and neutralizer cathodes of ion thrusters. ${ }^{27}$ A solid $2 \%$ thoriated tungsten rod cathode was tested but the arc discharge could not be sustained at the low pressures required for this study. The hollow cathode consisted of a low work function porous tungsten insert housed in a cylindrical $0.61 \mathrm{~cm}$ diameter $59 \%$ molybdenum- $41 \%$ rhenium body. The cathode body was closed using a $2 \%$ thoriated tungsten disc with a $0.15 \mathrm{~cm}$ diameter orifice in its center. The cathode was preheated to remove surface impurities and to condition the surface for ignition using a 
heater wrapped around the end of the hollow cathode. $^{27}$

Power for the arc discharge was provided by a DC supply coupled to a current regulator. This arrangement provided a maximum isolated output of $30 \mathrm{~A}$ at $150 \mathrm{~V}$. Current and voltage ripple at different operating conditions are listed in Table 1. The current shunt used to measure ripple was significantly affected by electromagnetic noise when the ripple exceeded $10 \%$ and these values were, therefore, not included.

Two electromagnets, made of wire coiled around a mild steel cylindrical core, were used to create a uniform magnetic field across the surface of the anode. The electromagnets were oriented with their centerlines aligned and separated by $12.7 \mathrm{~cm}$ with the anode surface at the center. The electromagnets were mounted on a stand that allowed them to be rotated so that the angle between the anode surface and the magnetic field lines could be varied. A maximum field strength of $8.60 \mathrm{mT}$ could be maintained at the anode surface, comparable to the $30 \mathrm{mT}$ used in the MPD thruster in References 2, 11, and 16.

Tests were performed in a $0.53 \mathrm{~m}$ diameter, $0.36 \mathrm{~m}$ long vacuum facility that was evacuated using a turbo-molecular-roughing pump combination capable of pumping $260 \mathrm{~V} / \mathrm{sec}$ of air at a pressure of $1 \mathrm{~Pa}$ ( $10^{-2}$ torr). A schematic of the pumping system is shown in Figure 5. The pumping system provided a facility base pressure near $10^{-3} \mathrm{~Pa}\left(10^{-5}\right.$ torr) with no gas flow. Two independent gas injection ports were utilized. The first fed gas into the hollow cathode while the second fed gas into the vacuum facility through a gas diffuser. This arrangement allowed the pressure at the anode to be varied without altering the cathode flow rate. Furthermore, a pressure control baffle was placed at the juncture between the test facility and the port to the turbo-molecular pump to restrict the flow to the pumps and permit high pressure operation without damaging the turbo-molecular pump.

\section{Diagnostics}

Arc current and voltage were measured with a shunt and digital voltmeter, respectively, to within $0.1 \mathrm{~A}$ and $0.1 \mathrm{~V}$, respectively. The water flow rate to the anode and inlet and outlet temperatures were measured with a flow meter and Type $\mathrm{K}$ thermocouples, respectively, to calorimetrically determine the power deposited to the anode. The anode surface pressure was measured by a pressure tap positioned $1.3 \mathrm{~cm}$ to the side of the anode edge and coupled to a capacitance manometer. The anode surface temperature was measured with a single color optical pyrometer whenever possible. The brightness temperature was converted to the true surface temperature by accounting for the emittance of the anode surface and the transmittance of the plasma and quartz window, ${ }^{28}$ which were taken as $0.40,1.0$, and 0.90 , respectively. Changes in surface emittance by \pm 0.05 would result in an error of $-15^{\circ} \mathrm{C}$ to $+18^{\circ} \mathrm{C}$ for the range of measured surface temperatures. This measured surface temperature was used to determine anode surface radiation which was used with the calorimetric measurements to calculate the total power deposited to the anode.

The electron temperature, electron number density, and plasma potential were measured using a single Langmuir probe located $0.2 \mathrm{~cm}$ to the side of the anode as shown in Figure 4. Measurements of plasma potential and electron temperature were used to estimate terms in Equation 1 and to compare them to the measured anode power deposition. The electron number density and electron temperature were used to correlate the anode fall voltage with the thermal electron current and Hall parameter. ${ }^{10,23,24}$ The probe circuit diagram is shown in Figure 6. The probe was a $0.508 \mathrm{~mm}$ diameter, $2 \mathrm{~mm}$-long, $2 \%$ thoriated tungsten wire. Current continuity to the plasma was maintained by a $97 \mathrm{~cm}^{2}$ tantalum plate, shown in Figure 3, that was placed in the plasma. The large area was necessary to avoid double probe effects. ${ }^{29}$ The voltage between the tantalum plate and the anode was measured with a digital voltmeter to determine the local plasma potential relative to the anode (i.e. the anode fall voltage). Current-voltage characteristics were collected by ramping the voltage of a bipolar power supply to $\pm 40 \mathrm{~V}$ with a function generator set to a $100 \mathrm{~Hz}$ frequency and a triangular wave form. This frequency was chosen to avoid drawing the electron saturation current for an extended period and possibly over-heating the probe. The probe temperature never exceeded $1200^{\circ} \mathrm{C}$, ensuring that probe thermionic emission effects were negligible.

The single Langmuir probe measurements were obtained by collecting seven complete currentvoltage characteristics at a given operating condition and storing them on a digital oscilloscope with a sampling frequency of $1 \mathrm{MHz}$. These characteristics were reduced to electron temperatures, number densities, and plasma potentials using simple electrostatic probe theory,,$^{30,31}$ where: 


$$
\begin{gathered}
T_{e}=\frac{e}{k}\left(\frac{d \ln \left|J_{p}-J_{i s a t}\right|}{d V_{p}}\right)^{-1}, \\
n_{e}=\frac{J_{\text {esat }}}{e A_{p} \sqrt{k T_{e} / 2 \pi m_{e}}},
\end{gathered}
$$

and the plasma potential, $\mathrm{V}_{\mathrm{pl}}$, was found from the "knee" of the probe characteristic as shown in Figure 7. Results for the seven current-voltage characteristics were averaged to obtain the reported values. Use of simple probe theory was justified because the electron mean free paths and Debye lengths were greater than and less than the probe radius, respectively. Magnetic field effects were neglected because the electron Larmor radii were greater than the probe radius for all applied magnetic field strengths tested.

\section{Procedure and Operating Conditions}

A typical test series involved evacuation of the test facility, preheating the cathode, arc ignition, data collection, arc termination, and cathode cooldown. The test facility was evacuated to a pressure of $10^{-3} \mathrm{~Pa}\left(10^{-5}\right.$ torr) for a minimum of 12 hours prior to testing to allow for outgassing. The cathode was then heated to remove contaminants and conditioned for ignition. ${ }^{27}$ The pressure baffle control was then closed, and argon was injected through the hollow cathode to bring the facility pressure to $13 \mathrm{~Pa}(0.10$ torr). The main power supply was set to $6.5 \mathrm{~A}$ with an open circuit voltage of $125 \mathrm{~V}$ for ignition. The arc was ignited using a high voltage ignitor supply that provided $1000 \mathrm{~V}$ with a 1 A rectified current. After ignition, the ignitor and cathode heater supplies were turned off, the current was raised to $8 \mathrm{~A}$, and the facility pressure lowered to $4 \mathrm{~Pa}$ ( 0.03 torr) by reducing gas flow to the cathode. The arc was maintained at this condition for one hour to allow the test hardware to reach thermal equilibrium. Following arc termination, gas was purged into the hollow cathode for 3 hours to prevent contamination of the low work function insert.

The arc current was varied from 6 to $15 \mathrm{~A}$ and the anode surface pressure was varied from 1.3 to $67 \mathrm{~Pa}(0.01$ to 0.50 torr). This pressure was varied with the pressure baffle control and with gas injection into the facility. Gas feed to the hollow cathode was not varied to avoid changes in hollow cathode characteristics, particularly those associated with transitioning from plume to spot modes of operation.2 The magnetic field strength was varied from 0 to $8.60 \mathrm{mT}$ at the anode surface, with the magnetic field orientation at $0^{\circ}, 21^{\circ}$, and $40^{\circ}$ with respect to the anode surface. The anode utilized for this study was made of porous tungsten impregnated with a 4:1:1 molar ratio of $\mathrm{BaO}, \mathrm{CaO}$, and $\mathrm{Al}_{2} \mathrm{O}_{3}$ with a work function of about $2 \mathrm{eV}$. While an attempt was made to vary the anode surface work function, the test results were inconclusive.

\section{Experimental Results and Discussion}

The following sections examine the effects of pressure, arc current, and applied magnetic field strength and orientation on anode power deposition. An effective anode fall voltage, $V_{\mathrm{efr}}$, given by:

$$
V_{\text {eff }}=\frac{P_{a}}{J_{\text {arc }}} .
$$

was used to describe the anode power deposition and to simplify comparisons between the measured anode power and the local plasma properties. The discharge operating envelope was determined by arc stability at low pressures and currents, and by heat transfer at high currents. The arc current and applied magnetic field strength were limited to $15 \mathrm{~A}$ and $8.6 \mathrm{mT}$, respectively, because of temperature restrictions on the hollow cathode and magnet coils. Worst-case standard deviations for effective anode voltages, anode fall voltages, electron temperatures, and electron number densities were $0.48 \mathrm{~V}, 0.61 \mathrm{~V}, 0.14 \mathrm{eV}$, and $2.1 \times 10^{16} \mathrm{~m}^{-3}$, respectively, for operation without an applied magnetic field. The plasma potential near the anode was always negative with respect to the anode (see Figure 2) so that, by convention, the anode fall voltage was positive.

\section{Effect of Anode Surface Pressure}

The effect of anode surface pressure on anode power deposition is shown in Figure 8 for arc currents of $6,8,10$, and $12 \mathrm{~A}$ without an applied magnetic field. The effective anode voltage remained approximately constant for each current level at pressures greater than $7.5-13 \mathrm{~Pa}(0.05-0.10$ torr) but increased significantly below this pressure. The rise in effective anode voltage with decreasing anode pressure has been previously documented for coaxial electrode configurations. ${ }^{8,9,25}$ The data from this study confirmed that operation at increased anode surface pressures reduces anode power deposition. In addition, three modes of anode arc attachment were observed. The pressure regimes where these modes 
occurred are also shown in Figure 8. A well-defined blue plasma bubble with a violet border formed above the anode at pressures below 5.3-6.7 $\mathrm{Pa}(0.04-0.05$ torr) with the bubble size decreasing with increasing pressure. At higher pressures, a diffuse violet plasma bubble appeared over the entire anode. At pressures above 15-24 $\mathrm{Pa}$ (0.11-0.18 torr), the arc attachment suddenly changed to a blue spot about $1 / 4-1 / 3$ the anode diameter. The spot diameter increased with increasing pressure to about $1 / 2$ the anode diameter, and then changed to a coaxial tubular shape. It is not clear what caused these different anode arc attachment modes.

The effect of anode surface pressure on the local plasma properties is shown in Figures 9 and 10 for arc currents of $6 \mathrm{~A}$ and $12 \mathrm{~A}$ without an applied magnetic field. The anode fall voltage, electron temperature, and electron number density generally followed the same trend as the effective voltage, with values increasing at lower pressures. The predicted effective anode fall voltage, found assuming negligible contributions from emitted electrons, ions, radiation, and convection, is given by:

$$
V_{\text {effpre }}=\frac{5 k T_{e}}{2 e}+V_{\text {fall }}+\phi .
$$

Results shown in Figure 11 indicate that the anode fall voltage accounted for $49-67 \%$ of the predicted effective anode voltage. while the electron temperature and work function accounted for $21-38 \%$ and 9 $13 \%$, respectively. The predicted effective anode voltage was greater than the measured value, and the disparity increased with increasing arc current. This disparity will be discussed in the next section. In general, the data confirmed the dominance of the current-carrying electrons in anode power deposition and demonstrated that the anode fall voltage accounted for the majority of this deposition.

A possible explanation for the observed pressure dependence of the anode power deposition is given. Assuming that the current is dominated by the electron current, its magnitude in the arc column can be estimated from the random thermal flux of electrons. The random thermal electron current was determined by assuming that the anode sheath thickness was small compared to the anode so that a onedimensional electron continuity equation could be used. The ratio of the random thermal electron current to the imposed anode current for a varying anode surface pressure is shown in Figure 12. As shown in the figure, this ratio never reaches unity.
Thus, in order for the electron current to equal the imposed anode current, either the anode sheath had to become large enough for two-dimensional effects to be important, and/or ionization was occurring in the vicinity of the anode. At the lower anode surface pressures, the observed plasma bubble may have been an anode double layer, very similar to that examined by Song, et $\mathrm{al}^{33}$ Within an anode double layer, ionization occurs to maintain the imposed anode current. As the anode surface pressure increased, the size of the bubble decreased, also documented by Song, et al., ${ }^{33}$ due to the increased probability of ionization. Since the Langmuir probe was in the vicinity of the double layer, enhanced electron number densities were measured. The decrease in anode fall voltage with increasing pressure was further documented by Song, et al..$^{34}$ in another study where the double layer was magnetized for arc stability. Unfortunately, neither of Song's studies explored pressures in the $6.7-13.3 \mathrm{~Pa}(0.05-0.10$ torr) range as reported in this study. Within this range, the anode double layer may collapse due to the decreased electron-neutral mean free path, and the ionization needed to maintain the imposed anode current occurred in the vicinity of the anode sheath. The Langmuir probe may not have been within this vicinity and therefore did not measure the enhanced electron number densities.

\section{Effect of Arc Current}

The effect of arc current on the effective anode voltage is shown in Figure 13 for anode surface pressures of $1.3,6.7$, and $13 \mathrm{~Pa}(0.01,0.05$, and 0.10 torr) without an applied magnetic field. The effective anode voltage decreased slightly with increasing arc current at 6.7 and $13.3 \mathrm{~Pa}$ ( 0.05 and 0.10 torr). At $1.3 \mathrm{~Pa}(0.01 \mathrm{torr})$, the data were generally noisy and the arc current was limited to $9.8 \mathrm{~A}$ due to high anode surface temperatures. In general, however, anode power increased linearly with arc current, resulting in a constant effective anode fall voltage, so that operation at reduced arc currents decreased anode power deposition.

The effect of arc current on the anode fall voltage and electron temperature for anode surface pressures of 6.7 and $13 \mathrm{~Pa}(0.05$ and 0.10 torr) is shown in Figure 14. The anode fall voltage and electron temperature remained approximately constant for both pressures. The fall voltage accounted for 56$59 \%$ of the predicted effective anode voltage. while the electron temperature and work function accounted for $29-32 \%$ and $12-13 \%$, respectively. The effect of 
arc current on the electron number density is shown in Figure 15. The electron number density increased linearly with the arc current. Because the anode fall voltage and electron temperature did not vary with the arc current, current continuity at the anode was apparently maintained by a linear increase in the electron number density, which resulted in a linear increase in anode power deposition. This is a further indication of the dominance of the current-carrying electrons in anode power deposition. In addition, the results confirmed that the anode fall voltage accounted for over half of the anode power.

A comparison of the predicted and measured effective anode voltages as a function of the arc current is shown in Figure 16. While the measured voltage decreased slightly with increasing arc current, the predicted voltage increased slightly. Since this disparity increased with increasing arc current, it is likely that some heat was convected from the anode to the plasma and bell jar at higher arc currents and was not accounted for calorimetrically. This would also account for the disparity shown in Figure 11 .

\section{Effect of Applied Magnetic Field Strength and Orientation}

The effect of applied magnetic field strength on the measured and predicted anode fall voltage at two pressures with a constant arc current is shown in Figure 17. These data were taken with the magnetic field lines parallel to the anode surface. Agreement between the predicted effective anode fall voltage and the measured value was closer at $13 \mathrm{~Pa}$ ( 0.10 torr) than at $1.3 \mathrm{~Pa}(0.01$ torr $)$. At $1.3 \mathrm{~Pa}(0.01$ torr $)$, the difference increased with increasing applied magnetic field strength. The effective anode voltage increased much more rapidly at lower pressures than at higher pressures. The main contributor to this increase was the anode fall voltage, shown in Figure 18, which increased by $26 \mathrm{~V}$ at $1.3 \mathrm{~Pa}(0.01$ torr) and by $5 \mathrm{~V}$ at $13.3 \mathrm{~Pa}(0.10$ torr $)$. The electron temperature remained constant throughout. The effect of applied magnetic field strength on the electron number density is shown in Figure 19. The electron number density increased with increasing magnetic field strength and decreasing pressure. The data show that at lower anode surface pressures, anode power deposition increased with increasing applied magnetic field strength due to an increasing anode fall voltage.

The increase in the anode fall voltage with applied magnetic field strength indicates that the anode fall region was magnetized. The sheath surrounding the anode is considered magnetized when the electron gyro radius is comparable to or smaller than the Debye length and when the electron Hall parameter is greater than one. The former ratio is given by: ${ }^{10}$

$$
\frac{r_{l}}{\lambda_{D}}=\frac{7.5 \times 10^{-11}}{e B} \sqrt{m_{e} n_{e}} .
$$

The electron Hall parameter is the ratio of the electron cyclotron frequency to the electron-ion collision frequency in a partially ionized gas. ${ }^{10}$ In this study, however, the degree of ionization was on the order of $10^{-3}$ to $10^{-4}$ for anode surface pressures between 1.3 $\mathrm{Pa}$ and $13 \mathrm{~Pa}$ (0.01 torr and 0.10 torr), respectively, so that electron collisions with neutrals were significant. The electron Hall parameter was therefore modified to include the electron-neutral collision frequency, derived from Reference 35 , and is given by:

$$
\begin{gathered}
\Omega_{e}=\frac{\omega_{e e}}{v_{e-1}+v_{e-n}} \\
=\frac{1.8 \times 10^{11} B}{1.5 \times 10^{-12} \frac{n_{e} \ln (\Lambda)}{T_{e}^{1.5}}+4.1 \times 10^{-14} n_{n} \sqrt{T_{e}}\left(1.2 \sqrt{T_{e}}-1\right)} .
\end{gathered}
$$

Here, the electron-neutral collisional cross-section for argon was obtained from Reference 36 and is valid for electron temperatures between $1 \mathrm{eV}$ and $4 \mathrm{eV}$. Values of Larmor radius-to-Debye length ratios and electron Hall parameters for a variety of operating conditions are shown in Table 2 . These results show that for all operating conditions with applied magnetic field lines parallel to the anode surface, the electrons cycled about magnetic field lines many times before undergoing a collision. At a fixed arc current and applied field strength, low anode surface pressures resulted in a comparatively higher electron Hall parameter. This was because electron diffusion perpendicular to the magnetic field lines was restricted, thus conductivity perpendicular to the magnetic field lines decreased. The anode fall voltage increased to maintain the flux of electrons to the anode, and therefore increased the effective anode fall voltage. ${ }^{10}$ When the applied magnetic field angle was increased, electron diffusion along field lines enhanced the conductivity and decreased the anode fall voltage. At high anode surface pressures where the electron Hall parameter was low, electron diffusion perpendicular to the magnetic field lines was en- 
hanced by the increased electron-neutral collision frequency, and thus the conductivity in this direction was higher. As a result, the anode fall voltage, and therefore the effective anode fall voltage, was lower at high anode surface pressures. Similar trends had been observed in Reference 16. For this study, the electron gyro radii were always larger than the Debye length by 1-2 orders of magnitude, likely indicating that the anode fall region width was much greater than the Debye length. The electron Hall parameter, however, was an excellent trend indicator of applied magnetic field effects on anode power deposition when magnetic field lines were parallel to the anode surface.

The effect of applied magnetic field strength at different arc currents and a constant anode surface pressure on the measured and predicted effective anode fall voltage is shown in Figure 20. The difference between the measured and predicted effective anode fall voltages increased at higher arc currents due to heat convection to the plasma. The effect of applied magnetic field strength on the local plasma properties is shown in Figures 21 and 22. For the range of arc currents studied, applied magnetic field effects on the anode fall voltage, electron temperature, and electron number density were independent of arc current. This is further demonstrated in Table 2 where the Larmor radius-to-Debye length ratios and electron Hall parameters are comparable at $6 \mathrm{~A}$ and $12 \mathrm{~A}$ for an anode surface pressure of $13 \mathrm{~Pa}(0.10$ torr).

The effect of applied magnetic field orientation on the effective anode fall voltage at $1.3 \mathrm{~Pa}$ and 13.3 $\mathrm{Pa}(0.01$ torr and 0.10 torr) is shown in Figures 23 and 24 for arc currents of 6 and $12 \mathrm{~A}$, respectively. At $6 \mathrm{~A}$, the effective anode fall voltage was approximately the same for all orientations, especially at 13.3 (0.10 torr). This was also true at $12 \mathrm{~A}$ with a pressure of $13 \mathrm{~Pa}(0.10$ torr). However at $12 \mathrm{~A}$ and $1.3 \mathrm{~Pa}(0.01 \mathrm{t}$ torr), there was an abrupt change in the effective anode fall voltage with applied magnetic field orientation. At $0^{\circ}$, the effective anode fall voltage increased with increasing applied magnetic field strength, but at $21^{\circ}$ and $40^{\circ}$, the effective anode fall voltage decreased with increasing applied magnetic field strength. This indicates that operation with an applied field intercepting the anode surface reduces anode power deposition at high arc currents.

The effect of applied magnetic field strength on the anode surface temperature is shown in Figures 25 and 26. At $1.3 \mathrm{~Pa}$ (0.01 torr) and $6 \mathrm{~A}$ and $13 \mathrm{~Pa}$ (0.10 torr) and $12 \mathrm{~A}$, the anode surface temperature increased with increasing applied magnetic field strength. At $13 \mathrm{~Pa}$ (0.10 torr) and $6 \mathrm{~A}$, the anode surface temperature was not measurable. At $12 \mathrm{~A}$ and $1.3 \mathrm{~Pa}$, however, "runaway" conditions occurred in which the anode surface temperature rose quickly and threatened to damage the test hardware. As a result, data could not be taken at higher magnetic field strengths. This behavior is strange considering the decrease in the calorimetrically measured anode power and no explanation for it has been established.

The effects of applied magnetic field orientation on the local plasma properties are shown in Figures 27 and 28 at $12 \mathrm{~A}$ and $1.3 \mathrm{~Pa}$ (0.01 torr). The electron temperature remained the same for all orientations, but the anode fall voltage increased at $0^{\circ}$ and decreased at both $21^{\circ}$ and $40^{\circ}$ with increasing applied magnetic field strength. For all orientations, the electron number density increased with increasing applied magnetic field strength. The decrease in anode fall voltage with increasing applied magnetic field angle was likely due to magnetic field lines intersecting the anode, which increased plasma conductivity to the anode because the need for electron diffusion perpendicular to the magnetic field lines was reduced. These results showed that the reduction of anode power deposition with the applied magnetic field lines intercepting the anode was caused by a reduced the anode fall voltage.

\section{Conclusion}

A free burning arc was operated over a range of pressures, currents, and applied magnetic field strengths and orientations to identify the physics controlling anode power deposition and to establish techniques for reducing this loss. Operating conditions were chosen to duplicate those expected near the anodes of arcjets and MPD thrusters, however convective heat transfer was not simulated since there was no gas acceleration. Diagnostics included calorimetry for anode power, a single Langmuir probe for local plasma properties, and a pressure tap for anode pressures.

The results revealed that at a constant arc current, anode power decreased with increasing anode surface pressure up to $6.7 \mathrm{~Pa}(0.05$ torr) and then became insensitive to pressure. The local plasma properties also followed this trend. Anode power deposition was dominated by the current-carrying electrons with the anode fall voltage contributing over half of the anode power. The effective anode fall voltage decreased slightly with increasing arc current. 
While the anode fall voltage and electron temperature remained relatively constant, the electron number density increased linearly with increasing arc current, further indicating the dominance of the currentcarrying electrons in anode power deposition. The difference between the predicted and measured effective anode voltages increased with increasing arc current due to heat convected from the anode. Anode power increased with increasing applied magnetic field strength. This increase was greater at lower anode surface pressures and was independent of the arc current. The increase in anode power was caused by an increase in the anode fall voltage. Applied magnetic field orientation had an effect only at high arc currents and low anode pressures where the effective anode fall voltage increased with the field aligned parallel to the anode, and decreased when the field intercepted the anode. The anode fall voltage was the cause of these changes in anode power.

These results demonstrated that anode power deposition can be reduced by operating at increased anode pressures, reduced arc currents and applied magnetic field strengths, and by designing an anode such that the magnetic field lines intercept its surface. More extensive plasma diagnostics in the anode fall region for measurements of local plasma properties and anode sheath thickness are needed in order to gain a better understanding of the physics involved. Anode electron thermionic emission should also be examined so that its effect on anode power deposition can be assessed.

\section{Acknowledgements}

The authors would like to acknowledge the technical assistance of Fred K. Jent, Gerald M. Hill, Vincent E. Satterwhite, and Gerald F. Schneider in the fabrication and assembly of the test facility and hardware.

\section{References}

1 Sankovic, J. M. and Curran, F. M., "Arcjet Thermal Characteristics," AIAA Paper 91-2456, June 1991.

2 Myers, R. M., "Applied-Field MPD Thruster Geometry Effects," AIAA Paper 91-2342, June 1991. 3 Gilland, J. H., "NEP Mission Sensitivities to System Performance," NASA Contractor Report 189059, December 1991.

4 Tahara, H., Kagaya, Y., and Yoshikawa. T., "Hybrid MPD Thruster with Axial and Cusp Magnetic
Fields," IEPC Paper 88-058, October 1988.

5 Schall, W., "Influence of Magnetic Fields on Anode Losses in MPD-Arcs," AIAA Paper 72-502, April 1972.

6 Shih, K. T. and Pfender, E., "Electrode Energy Transfer Mechanisms in a MPD Arc," AlAA Journal, Vol. 8, No. 2, February 1970, pp. 211-215.

$7 \quad$ Bose, T. K. and Pfender, E., "Direct and Indirect Measurements of the Anode Fall in a Coaxial Arc Configuration," AIAA Journal, Technical Notes, Vol. 7, No. 8, August 1969. pp. 1643-1645.

8 Shih, K. T., et al., "Experimental Anode Heat Transfer Studies in a Coaxial Arc Configuration," AIAA Journal, Vol. 6, No. 8, August 1968, pp. 14821487.

9 Myers, R. M., Kelly, A. J., and Jahn, R. G.. "Energy Deposition in Low-Power Coaxial Plasma Thrusters," Journal of Propulsion and Power, Vol. 7 , No. 5, September-October 1991, pp. 732-739.

10 Myers, R. M., Mantenieks, M., and Sovey, J., "Geometric Effects in Applied-Field MPD Thrusters," AIAA Paper 90-2669, July 1990.

11 Gallimore, A. D., et al., "Anode Power Deposition in an Applied-Field Segmented Anode MPD Thruster," AIAA Paper 91-2343, June 1991.

12 Gallimore, A. D., Kelly, A. J., and Jahn, R. G., "Anode Power Deposition in MPD Thrusters," IEPC Paper 91-125, October 1991.

13 Saber, A. J. and Jahn, R. G., "Anode Power Deposition in Quasi-Steady MPD Arcs," AIAA Paper 73-1091, October-November 1973.

14 Oberth, R. C. and Jahn, R. G., "Anode Phenomena in High-Current Accelerators," AIAA Journal, Vol. 10, No. 1, January 1972, pp. 86-91.

15 Mantenieks, M. A., et al., "Performance of a $100 \mathrm{~kW}$ Class Applied Field MPD Thruster," AlAA Paper 89-2710, July 1989.

16 Myers, R. M. and Soulas, G. C., "Anode power Deposition in Applied-Field MPD Thrusters," AJAA Paper 92-3463, July 1992.

17 Ecker, G., "Electrode Components of the Arc Discharge," Eregbn. der Exact. Naturw., Vol. 33, pp. 1-104, 1961.

18 Gallimore, A. D., Kelly, A. J., and Jahn, R. G., "Anode Power Deposition in Quasi-Steady MPD Thrusters," AIAA Paper 90-2668, July 1990.

19 Sanders, N. A. and Pfender, E., "Measurement of Anode Falls and Anode Heat Transfer in Atmospheric Pressure High Intensity Arcs." Journal of Applied Physics, Vol. 55, No. 3, February 1, 1984, pp. 714-722.

20 Sanders, N., et al., "Studies of the Anode Re- 
gion of a High-Intensity Argon Arc," Journal of Applied Physics, Vol. 53, No. 6, June 1982, pp. 41364145.

21 Ivashkin, A. B., Kozlov, N. P., and Reshetnikov, N. N., "Anode Processes in a Low-Voltage DC Arc at Reduced Pressure. Experimental Investigation of the Anode Energy Balance at Reduced Pressure," Teplofizika Vysokikh Temperatur, Vol. 17, No. 1, January-February 1979, pp. 10-15.

22 Dyuzhev, G. A., Shkol'nik, S. M., and Yur'ev, V. G., "Anode Phenomena in the High-Current Arc. I," Sov. Phys. Tech. Phys., Vol. 23, No. 6, June 1978, pp. 667-671.

23 Dyuzhev, G. A., Shkol'nik, S. M., and Yur'ev, V. G., "Anode Phenomena in the High-Current Arc. II," Sov. Phys. Tech. Phys., Vol. 23, No. 6, June 1978, pp. 672-677.

24 Merinov, N. S., et al., "Anode Processes with a Negative Potential Drop at the Anode," Sov. Phys. Tech. Phys., Vol. 21, No. 4, April 1976, pp. 467-472. $25 \quad$ Hugel, H., "Effect of Self-Magnetic Forces on the Anode Mechanism of a High Current Discharge," IEEE Transactions on Plasma Sciences, Vol. PS8, No. 4, December 1980, pp. 437-442.

26 Curran, F. M., Manzella, D. H., and Pencil, E. J., "Performance Characterization of a Segmented Anode Arcjet Thruster," AIAA Paper 90-2582, July 1990.

27 Verhey, T. R. and Patterson, M. J., "Microanalyses of Extended-Test Xenon Hollow Cathodes," AIAA Paper 91-2123, June 1991.

28 Griem, H. R., Plasma Spectroscopy, McGraw-Hill Book Company, New York, 1964, pp. 255261.

29 Keefer, D., "The Influence of Varying Plasma Potential on Langmuir Probe Characteristics", Unpublished, Center for Laser Applications, University of Tennessee Space Institute, September 1968.

30 Hutchinson, 1. H., Principles of Plasma Diagnostics, Cambridge University Press, Cambridge, 1987.

31 Myers, R. M.,et al., "A Preliminary Characterization of Applied-Field MPD Thruster Plumes," AIAA Paper 91-2339, June 1991.

32 Kaufman, H. R., "Technology of ElectronBombardment Ion Thrusters," Advances in Electronics and Electron Physics, Vol. 36, 1974, pp. 265-373.

33 Song, B., D'Angelo, N., and Merlino, R. L., "On Anode Spots, Double Layers, and Plasma Contactors," Journal of Physics D: Applied Physics, Vol. 24, May 1991.

34 Song, B., D'Angelo, N., and Merlino, R. L.,
"The Effect of a Magnetic Field Gradient on Anode Double Layers," Physica Scripta, Vol. 45, 1992.

35 Cambel, A. B., Plasma Physics and Magnetofluidmechanics, McGraw-Hill Book Company, New York, 1963, pp. 174-180.

36 Mitchner, M. and Kruger, C. H., Partially Ionized Gases, John Wiley \& Sons, New York, 1973, p. 103. 


\begin{tabular}{||l|l|l|l|l|l||}
\hline $\begin{array}{c}\text { Pressure } \\
{[\mathrm{Pa}]}\end{array}$ & $\begin{array}{c}\text { Mag. Field } \\
{[\mathrm{mT}]}\end{array}$ & $\begin{array}{c}\text { Arc J } \\
{[\text { Amps] }}\end{array}$ & $\begin{array}{c}\text { Arc V } \\
{[\text { Volts }]}\end{array}$ & $\begin{array}{c}\text { J Ripple }^{1} \\
{[\%]}\end{array}$ & $\begin{array}{c}\text { V Ripple } \\
{[\%]}\end{array}$ \\
\hline \hline 1.60 & 0 & 6.0 & 31.1 & 55 & 12 \\
\hline 8.80 & 0 & 6.0 & 25.5 & 7.5 & 0.40 \\
\hline 1.60 & 0 & 12.0 & 29.3 & - & 39 \\
\hline 12.9 & 0 & 12.2 & 19.9 & - & 45 \\
\hline 1.60 & 1.0 & 6.1 & 38.6 & - & 5.8 \\
\hline 12.8 & 8.6 & 6.1 & 31.3 & - & 53 \\
\hline 1.47 & 1.1 & 12.0 & 29.9 & 15 & 1.1 \\
\hline 12.4 & 8.6 & 11.7 & 27.1 & - & 72 \\
\hline \hline
\end{tabular}

Peak-to-peak percent of arc current shown.

Table 1: Current and Voltage Ripple of Power Supply

\begin{tabular}{||l|l|l|l|l|l|l|l|l||}
\hline \begin{tabular}{|}
\hline $\mathrm{J}_{\text {arc }}$ \\
{$[\mathrm{A}]$}
\end{tabular} & $\begin{array}{l}\mathrm{p} \\
{[\mathrm{Pa}]}\end{array}$ & $\begin{array}{l}\text { Field } \\
\text { Angle } \\
{[\text { deg. }}\end{array}$ & $\begin{array}{c}\mathrm{B} \\
{[\mathrm{mT}]}\end{array}$ & $\begin{array}{c}\mathrm{T}_{\mathrm{e}} \\
{[\mathrm{eV}]}\end{array}$ & $\begin{array}{c}\mathrm{n}_{\mathrm{e}} \\
{\left[10^{-17} \mathrm{~m}^{-3}\right]}\end{array}$ & $\mathrm{r}_{\mathrm{P}} \lambda_{\mathrm{D}}$ & $\Omega_{\mathrm{e}}$ & $\begin{array}{c}\mathrm{V}_{\text {fall }} \\
{[\mathrm{V}]}\end{array}$ \\
\hline \hline 6 & 1.3 & 0 & 8.70 & 4.0 & 5.6 & 38 & 55 & 40 \\
\hline 6 & 13 & 0 & 8.70 & 1.8 & 3.9 & 32 & 14 & 14 \\
\hline 12 & 13 & 0 & 8.70 & 2.2 & 7.1 & 43 & 10 & 13 \\
\hline 12 & 1.3 & 0 & 2.60 & 2.7 & 6.5 & 140 & 25 & 26 \\
\hline 12 & 1.3 & 21 & 1.10 & 2.9 & 7.1 & 340 & 10 & 14 \\
\hline 12 & 1.3 & 40 & 0.80 & 2.5 & 7.0 & 470 & 8.3 & 15 \\
\hline
\end{tabular}

Table 2: Electron Gyro Radius-To-Debye Length Ratios and Electron Hall Parameters at Various Operating Conditions 


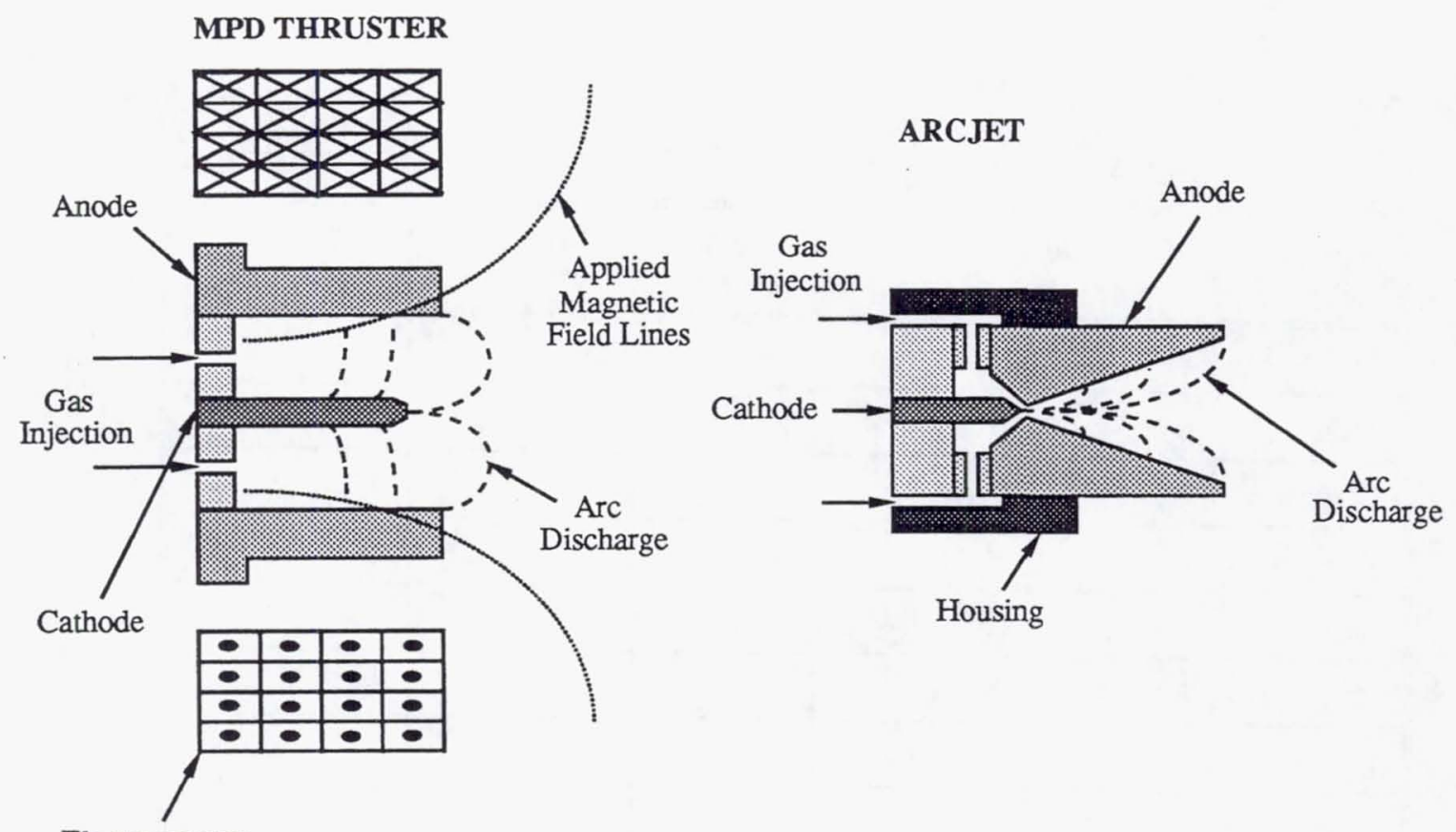

Electromagnet

Figure 1: Typical MPD thruster and arcjet designs.

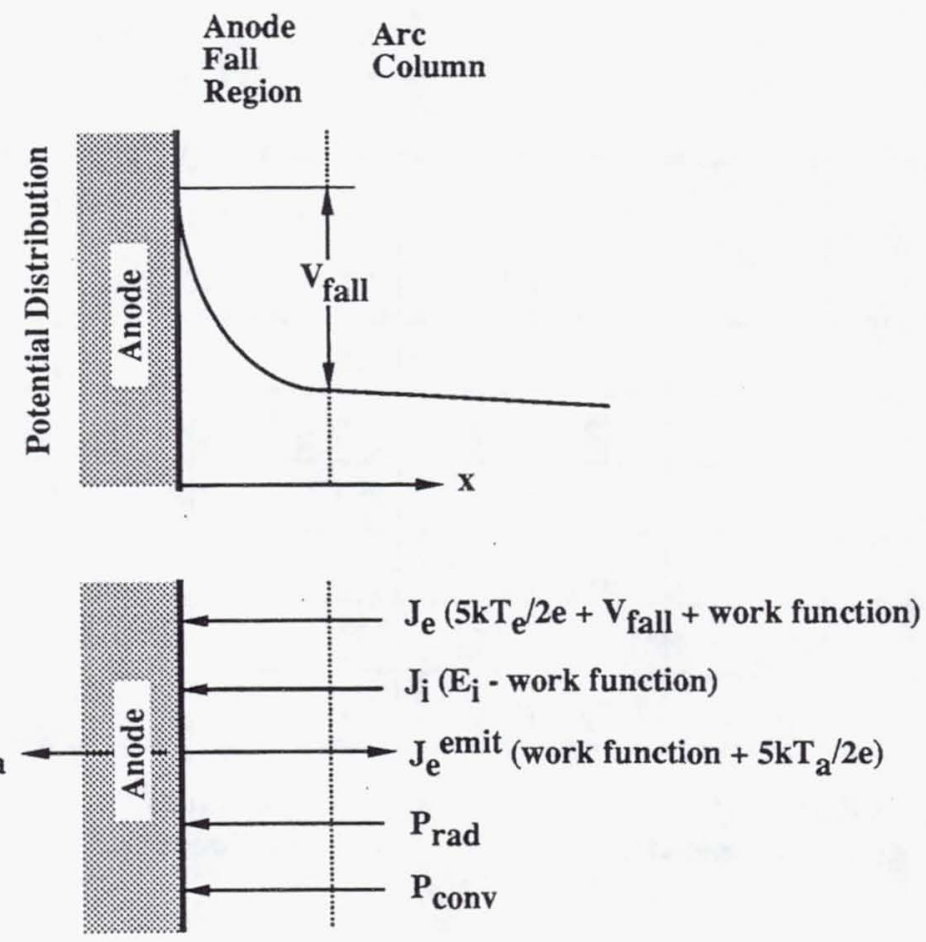

Figure 2: Potential distribution and energy balance at the anode of an arc. 


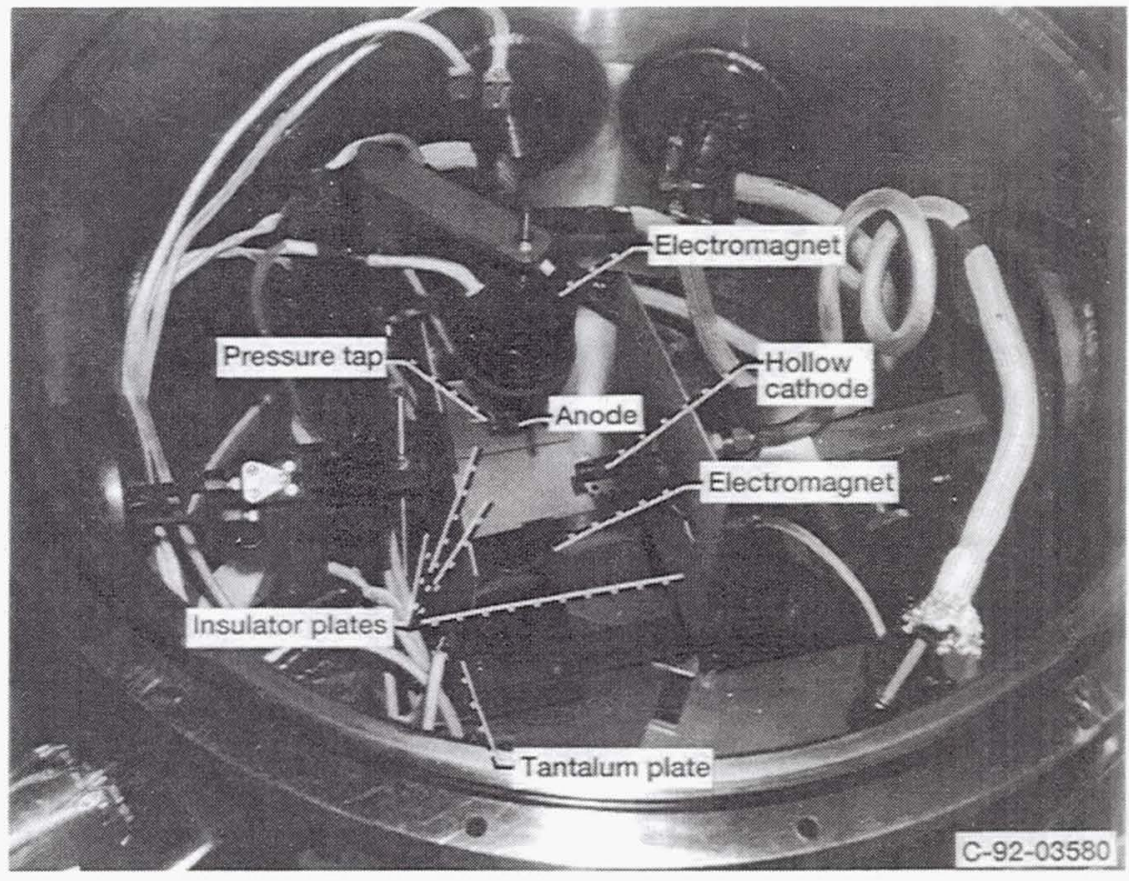

Figure 3: Test hardward including electrode geometry and electromagnets. 


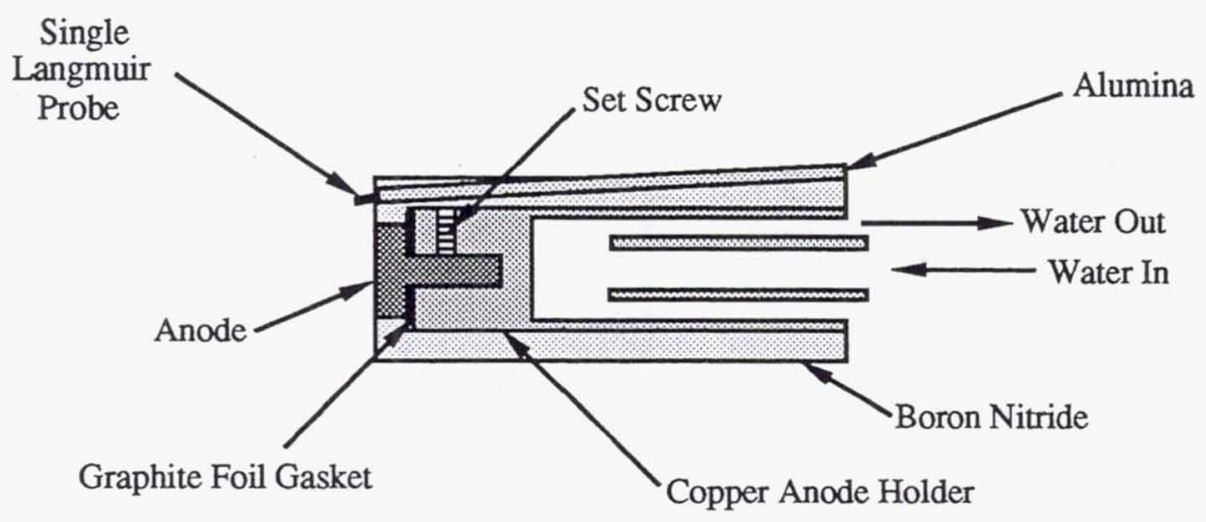

Figure 4: Schematic of anode and water cooling assembly.

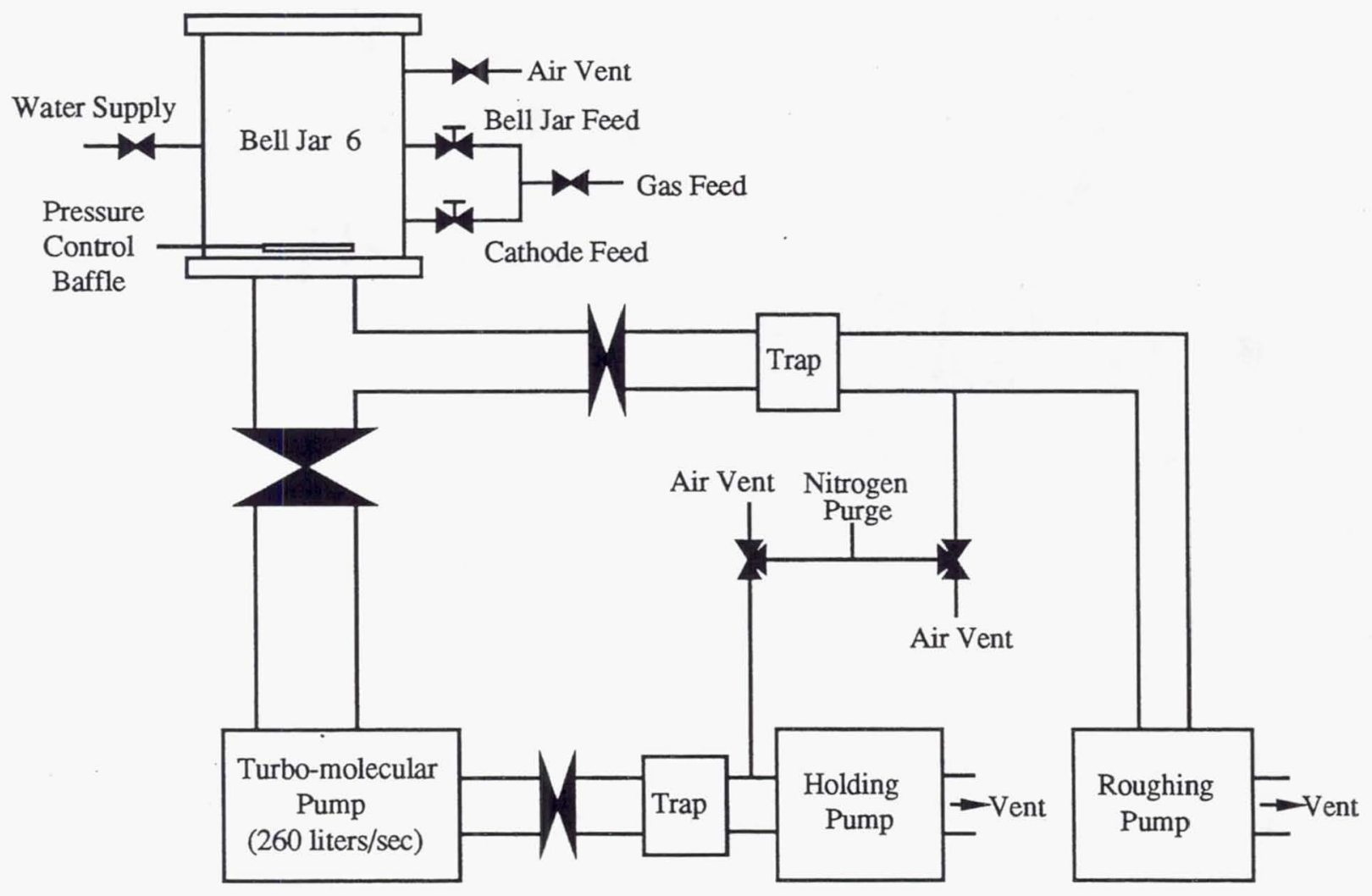

Figure 5: Vacuum facility pumping system schematic. 
Function Generator

$100 \mathrm{~Hz}$ Triangle Wave Form

(Isolated From Ground)

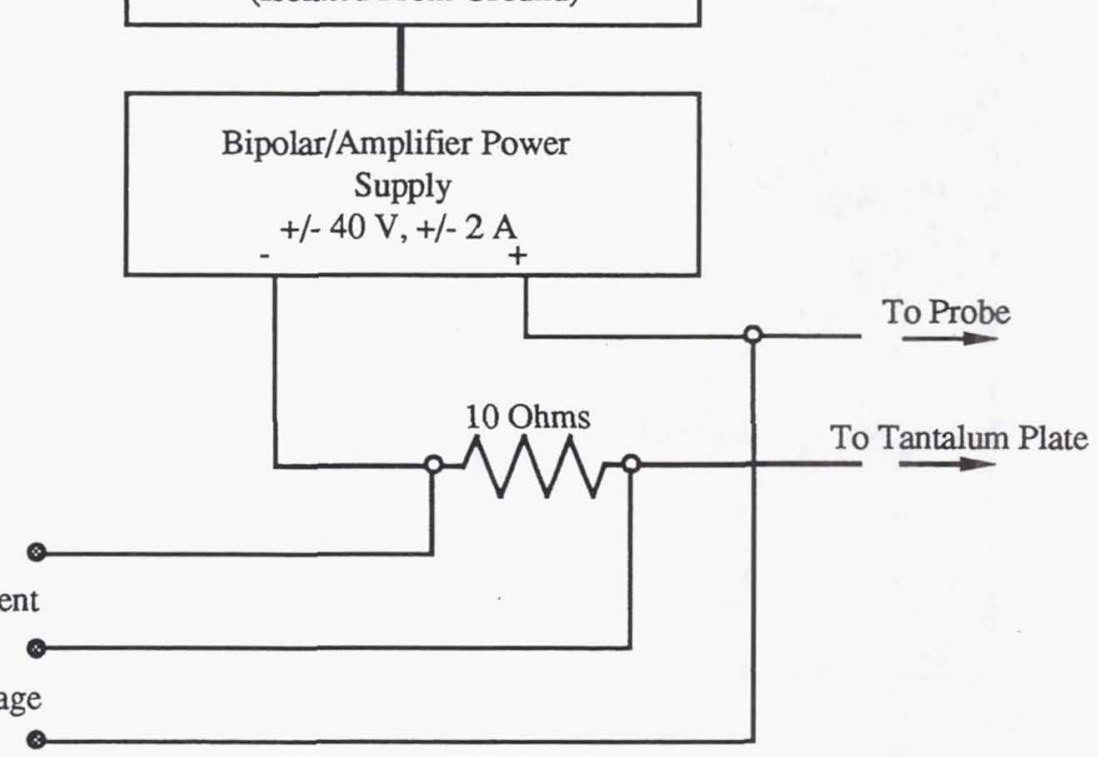

Figure 6: Single Langmuir probe circuit for electron temperatures, electron number densities, and plasma potentials.

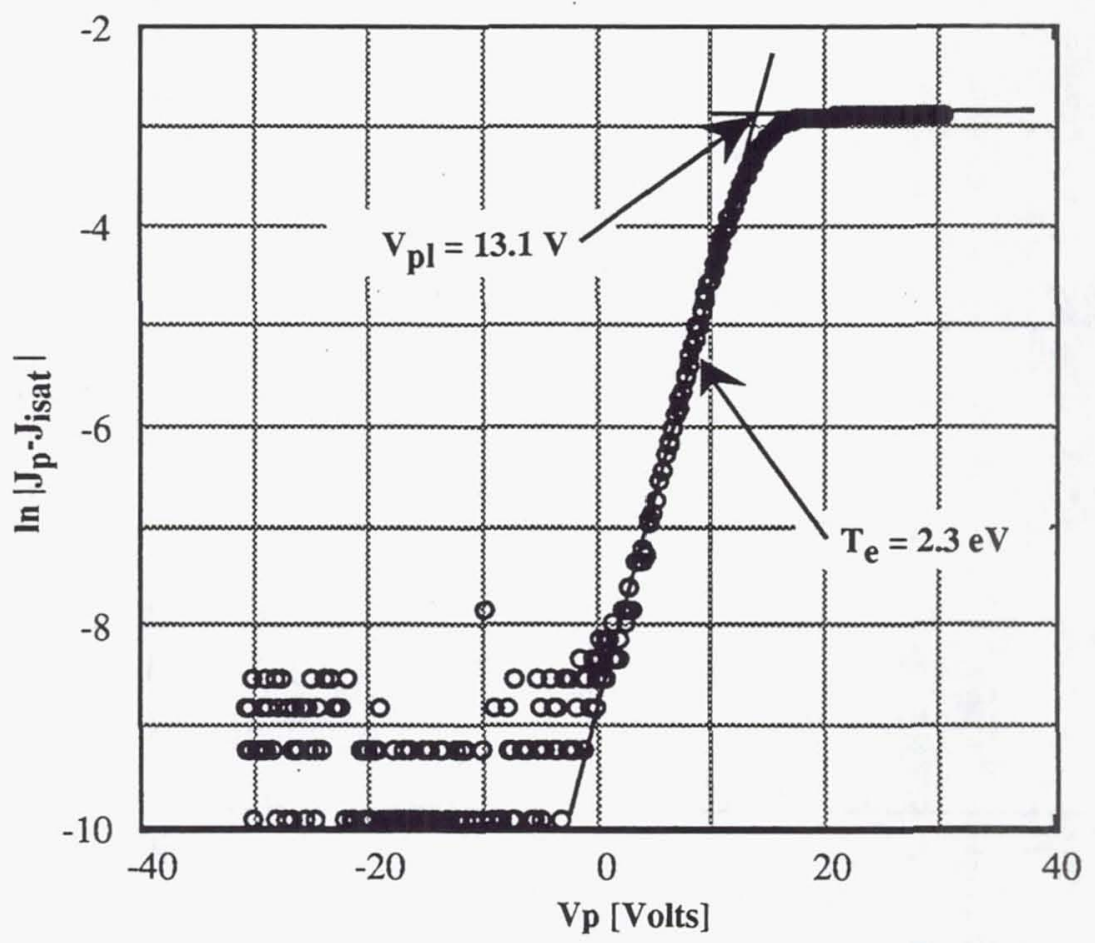

Figure 7: Current-voltage characteristic for the single Langmuir probe, $\mathrm{J}_{\mathrm{arc}}=10 \mathrm{~A}, \mathrm{p}=8.1 \mathrm{~Pa}$. 


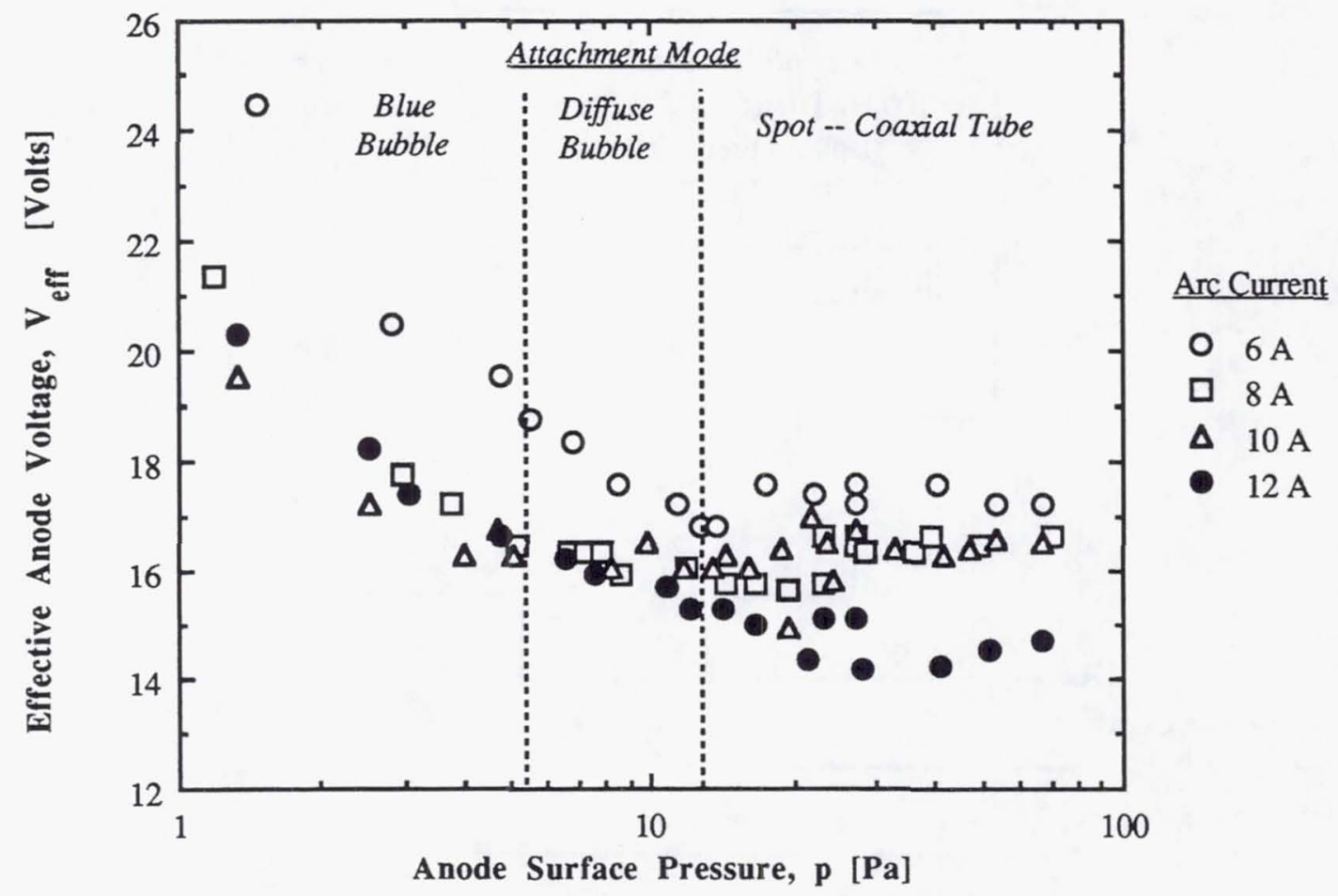

Figure 8: Effect of anode surface pressure on the effective anode voltage and anode arc attachment mode, $B=0$.

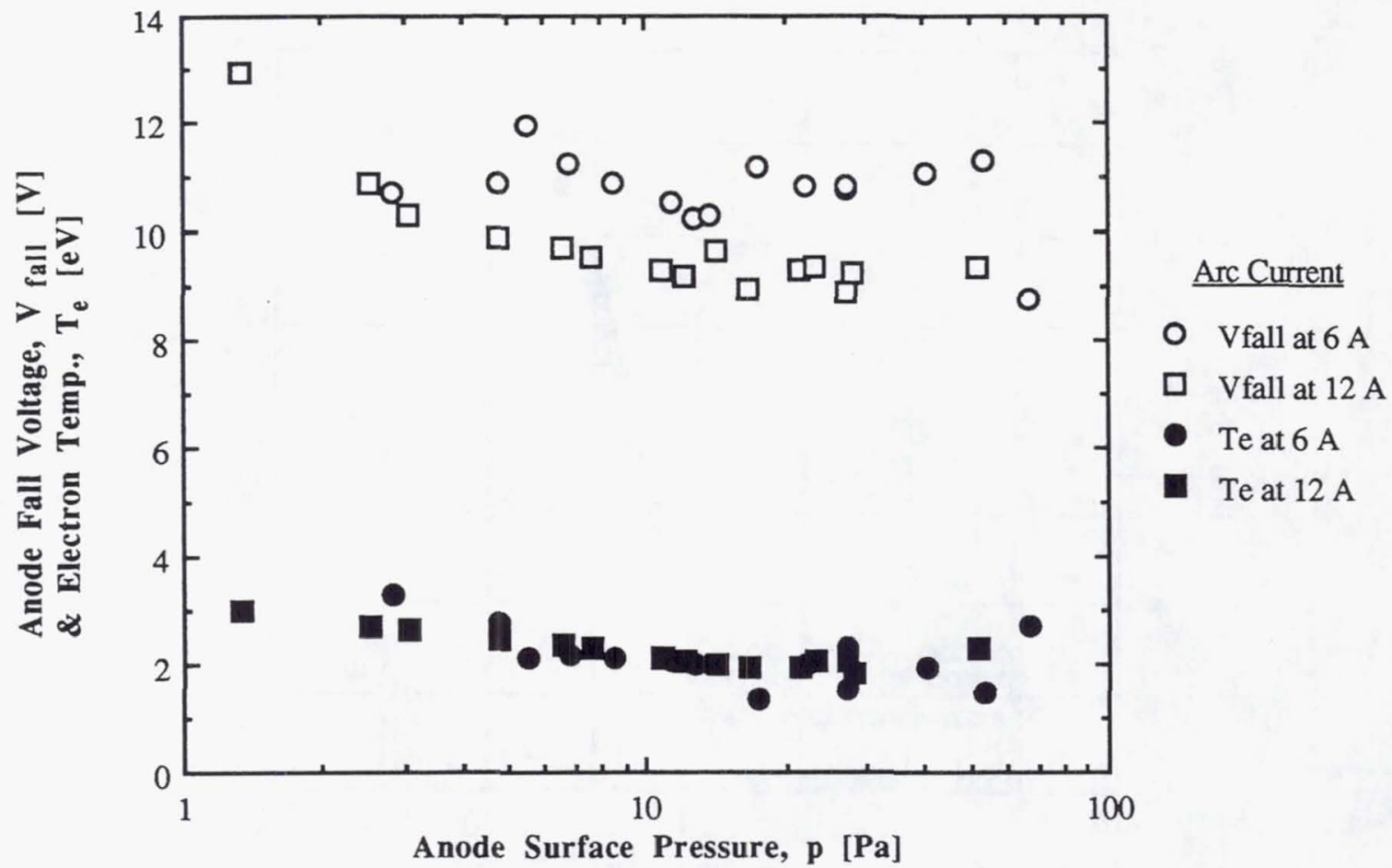

Figure 9: Effect of anode surface pressure on the anode fall voltage and the electron temperature, $B=0$. 


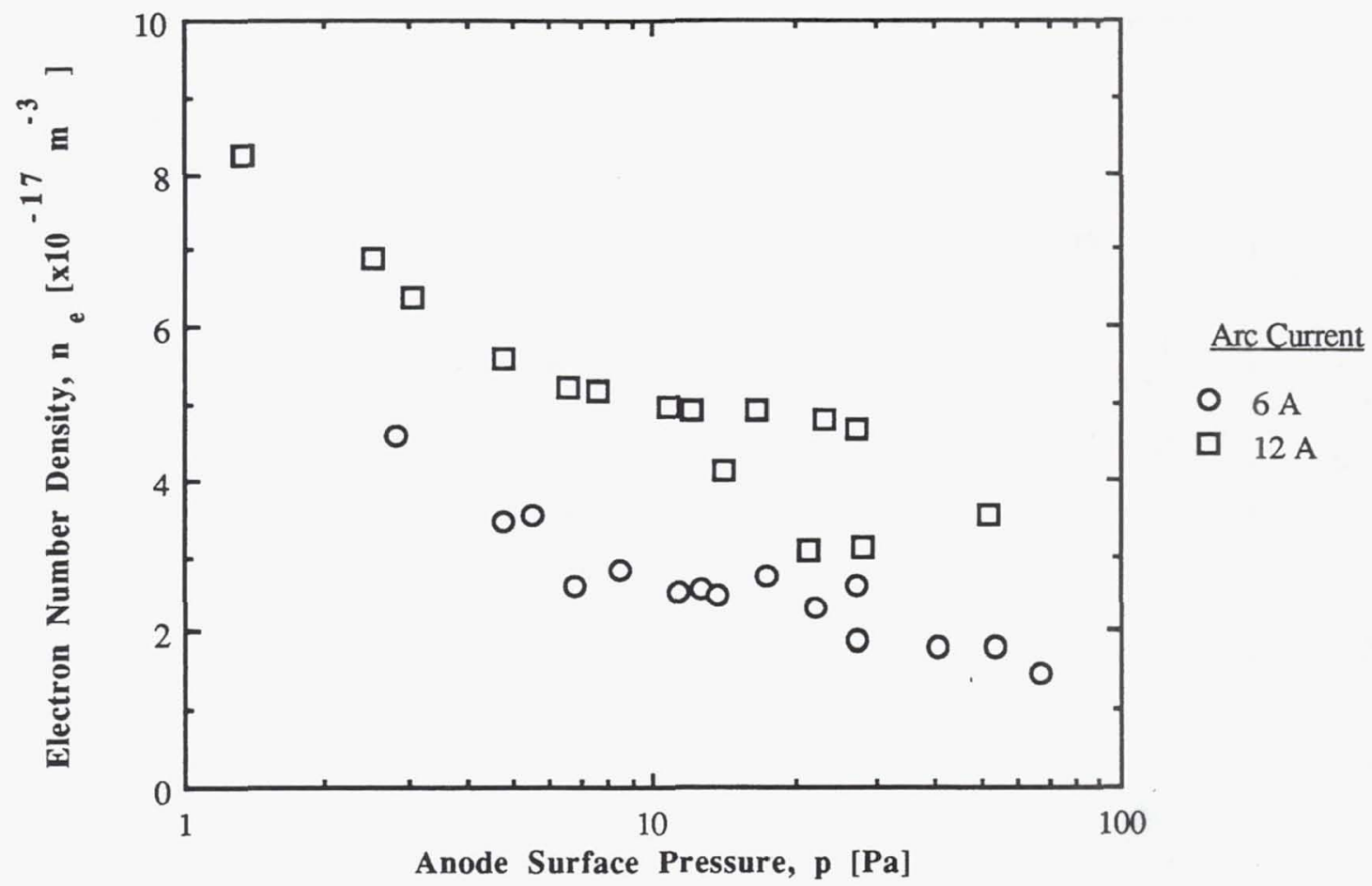

Figure 10: Effect of anode surface pressure on the electron number density, $B=0$.

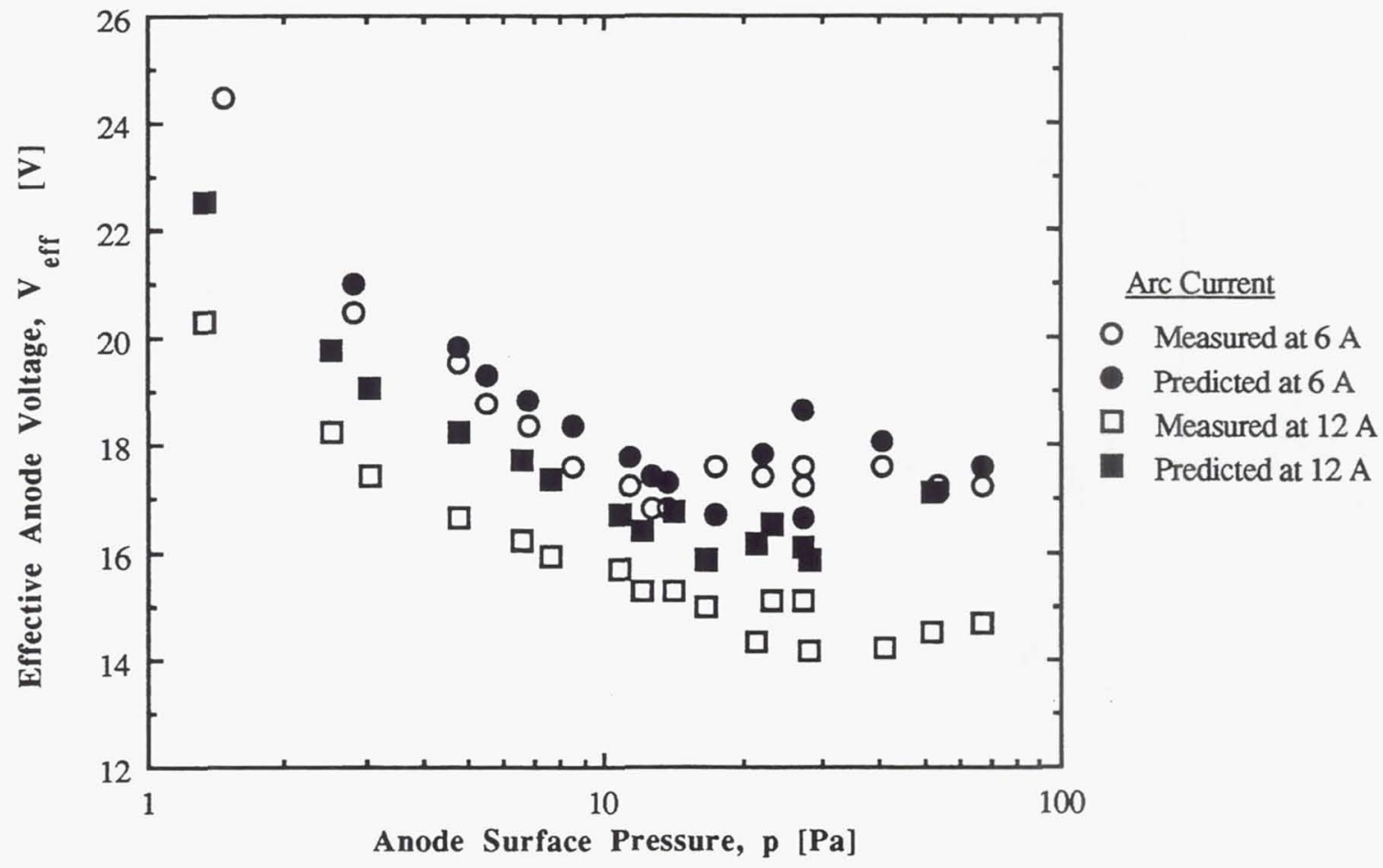

Figure 11: Effect of anode surface pressure on the measured and predicted effective anode voltage, $B=0$. 


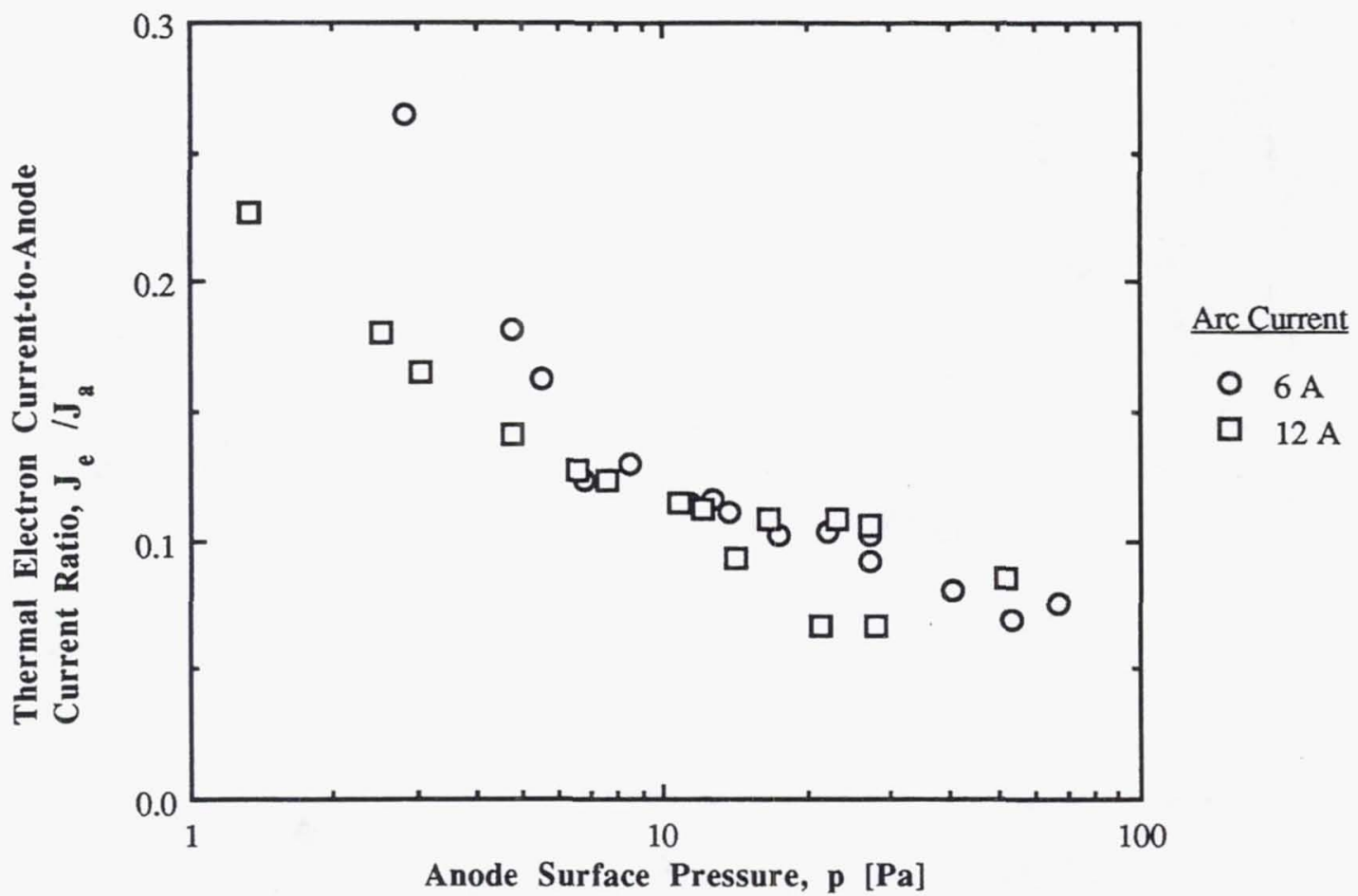

Figure 12: Effect of anode surface pressure on the anode and electron currents, $\mathrm{B}=\mathbf{0}$.

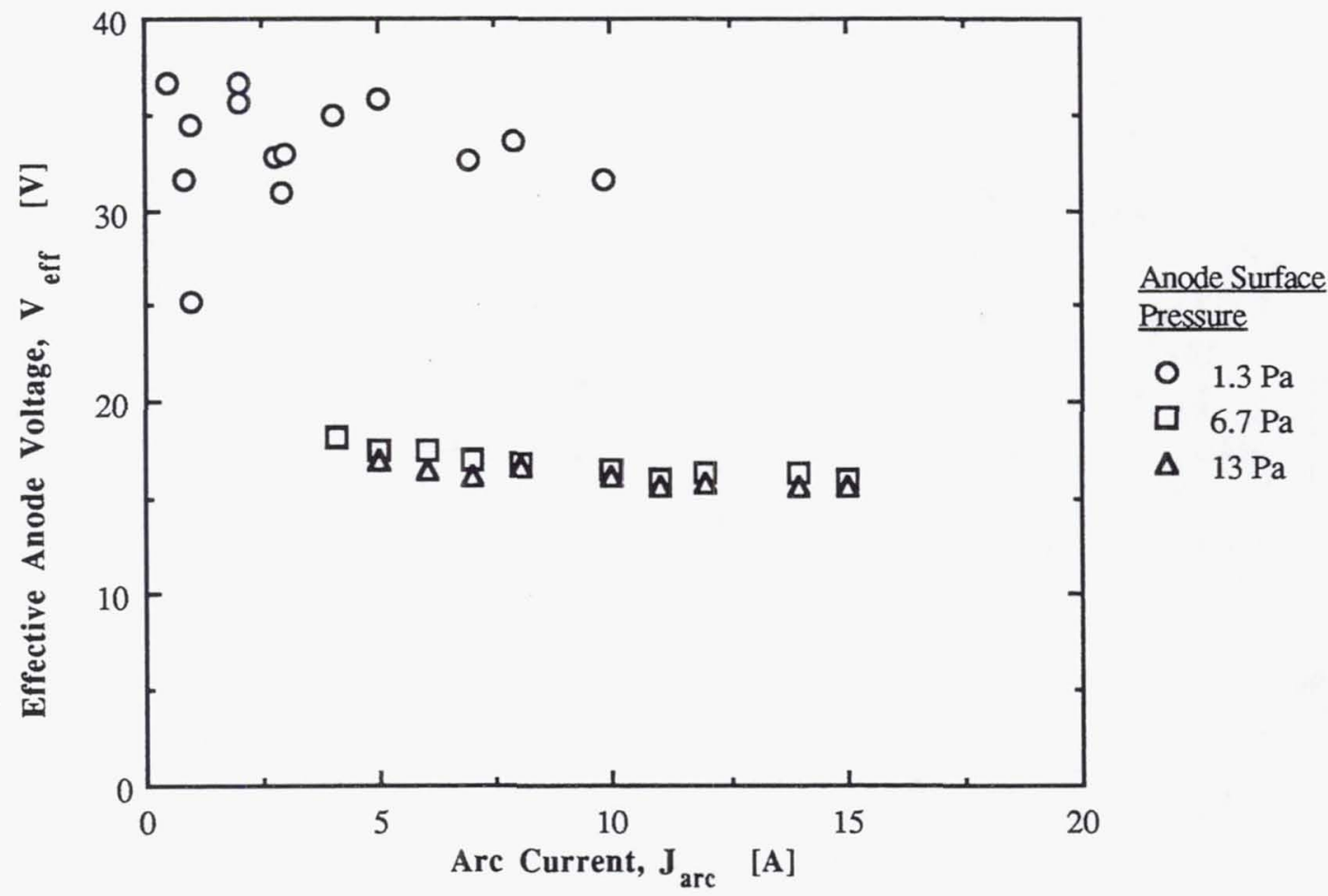

Figure 13: Effect of arc current on the effective anode voltage, $\mathbf{B}=\mathbf{0}$. 


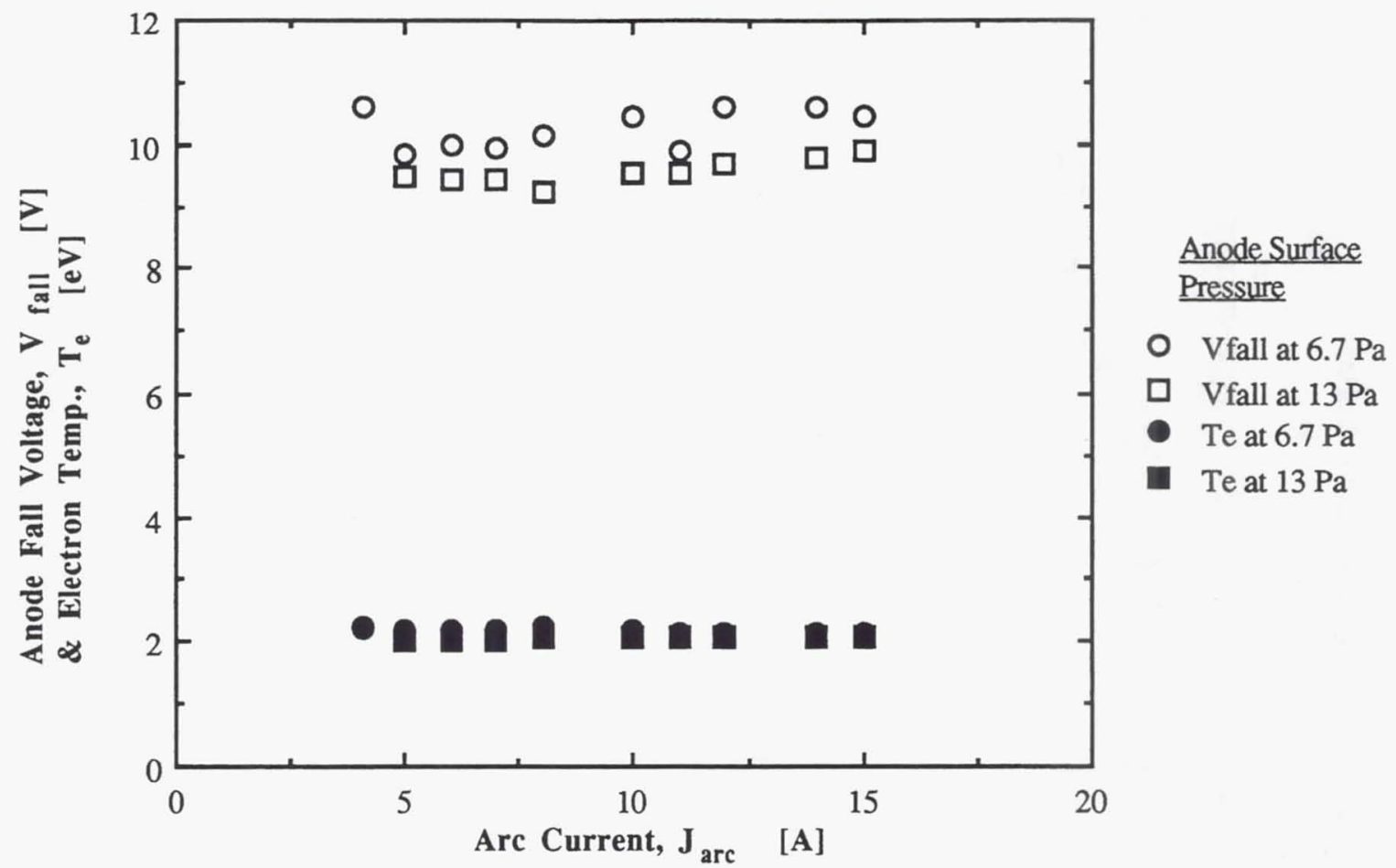

Figure 14: Effect of arc current on the anode fall voltage and the electron temperature, $\mathbf{B}=\mathbf{0}$.

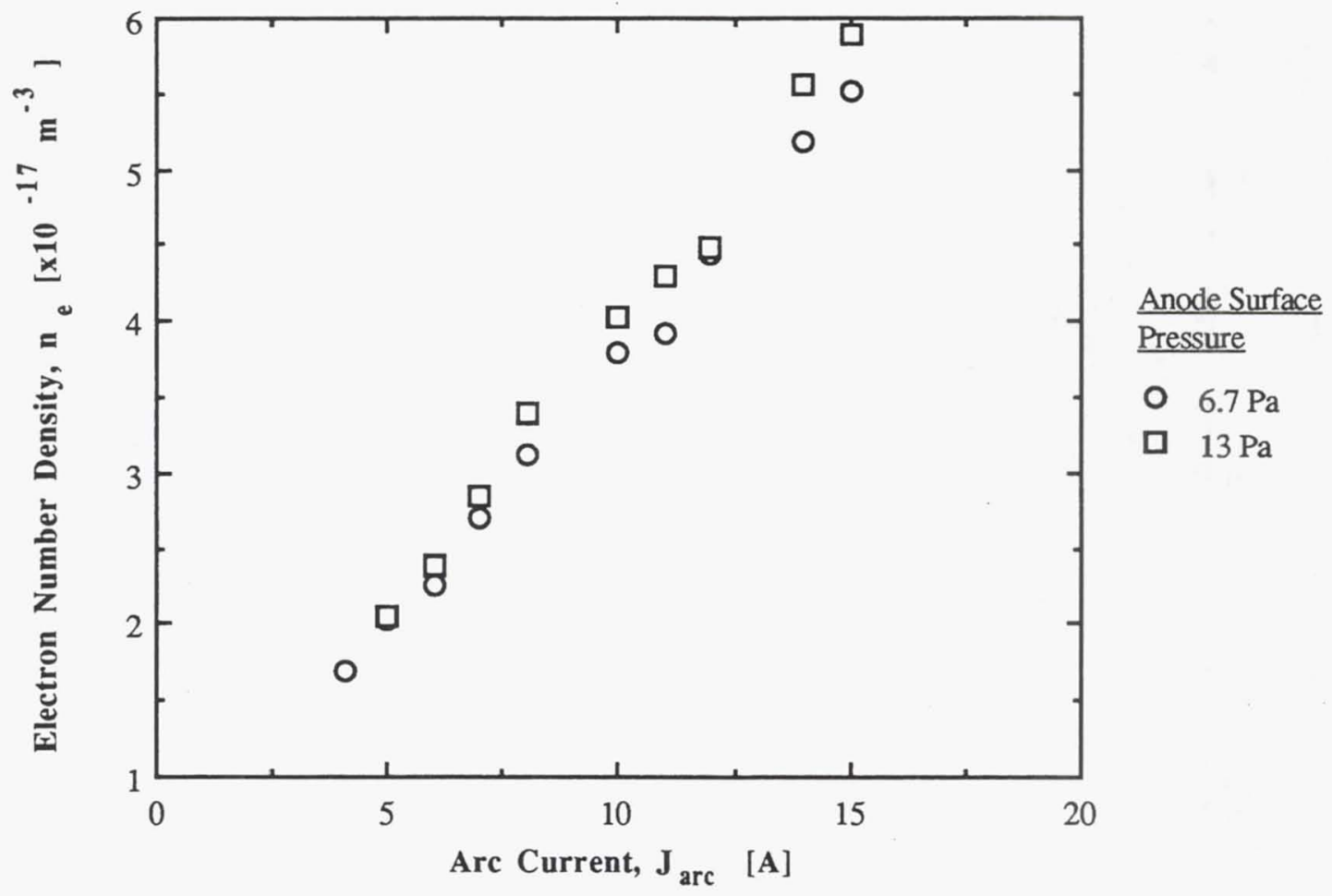

Figure 15: Effect of arc current on electron number density, $B=0$. 


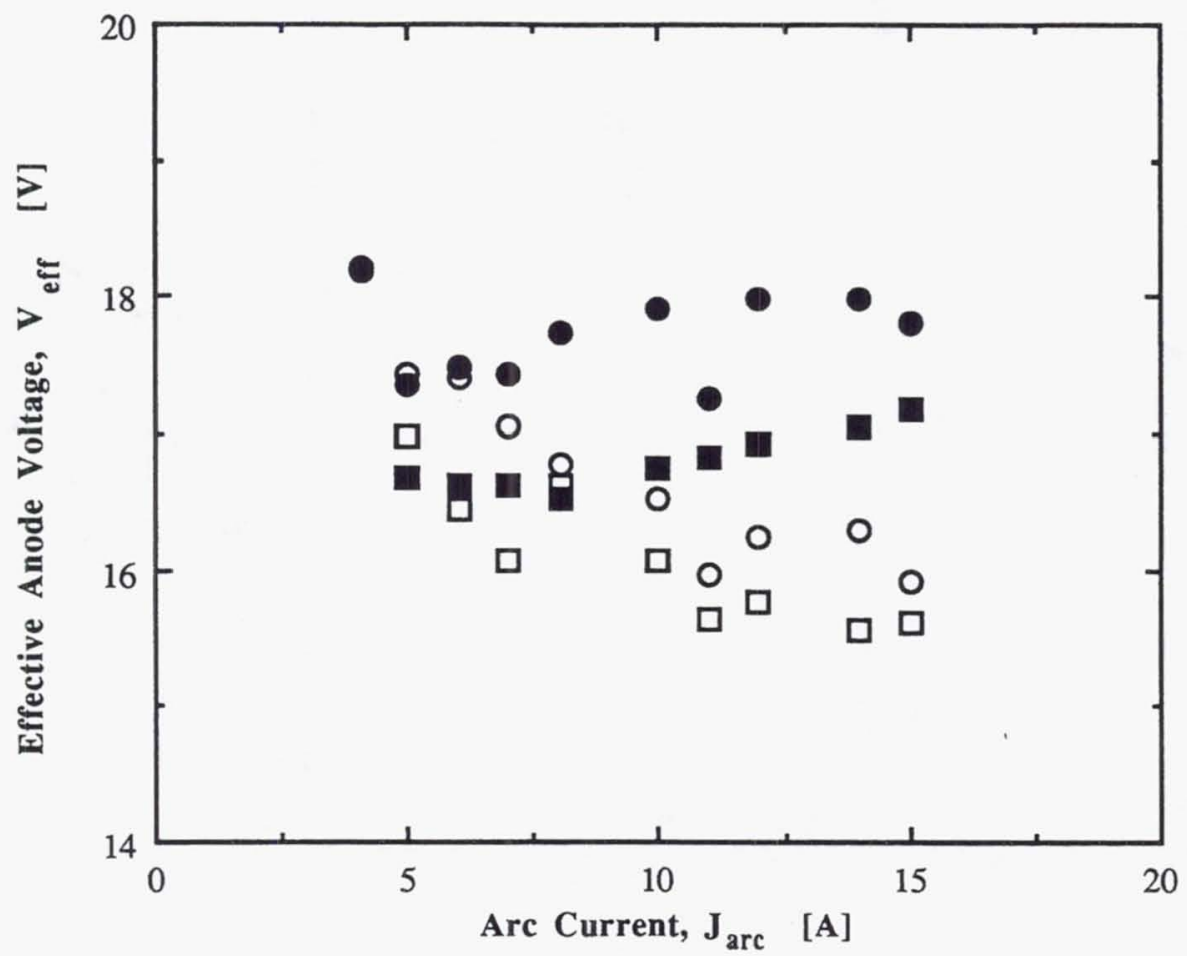

Anode Surface

Pressure

- Measured at 6.7 $\mathrm{Pa}$

- Predicted at $6.7 \mathrm{~Pa}$

D Measured at $13 \mathrm{~Pa}$

-1. Predicted at $13 \mathrm{~Pa}$

Figure 16: Effect of arc current on the measured and predicted effective anode voltage, $B=0$.

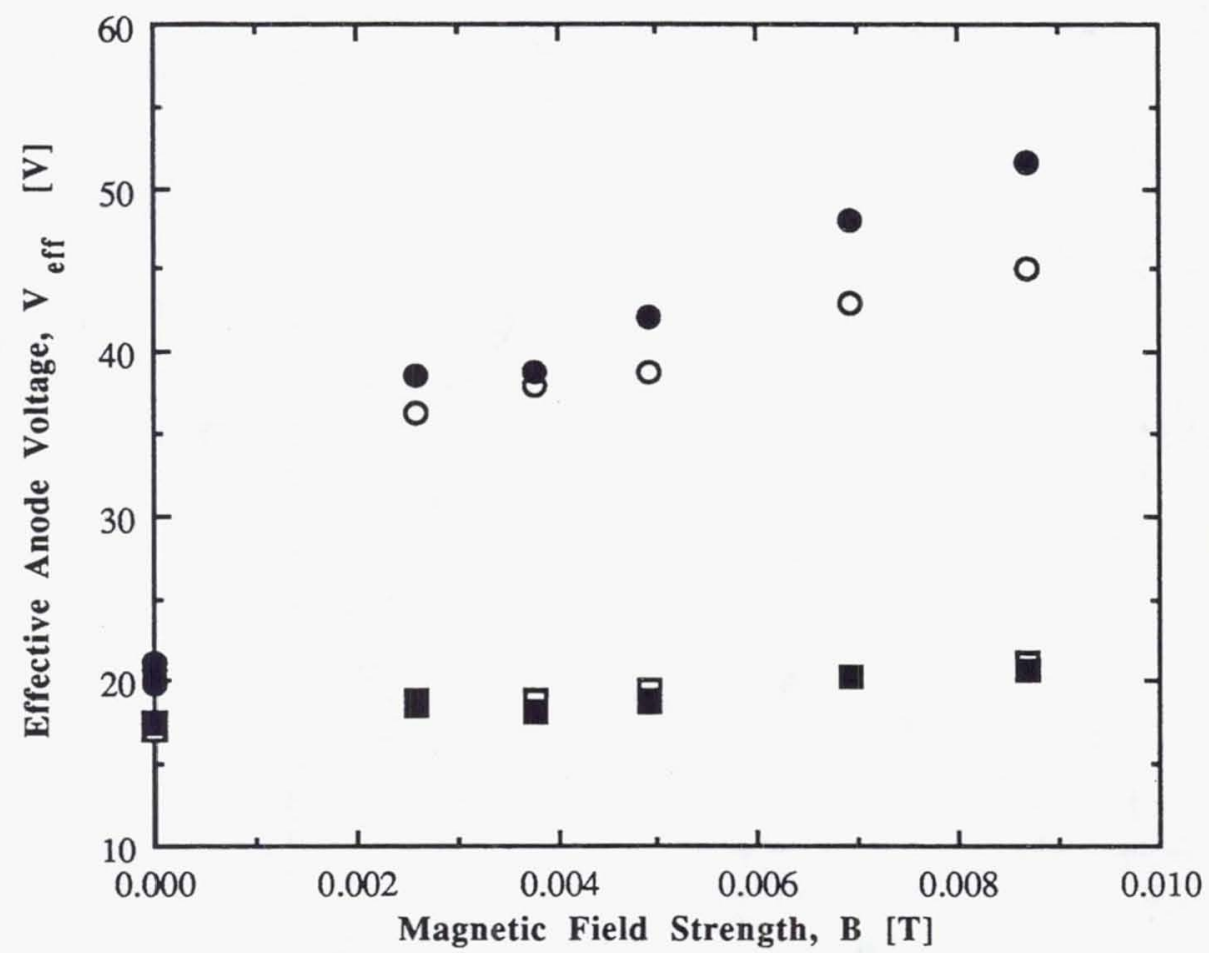

Anode Surface Pressure

- Measured at 1.3 Pa

- Predicted at $1.3 \mathrm{~Pa}$

․ Measured at $13 \mathrm{~Pa}$

- Predicted at $13 \mathrm{~Pa}$

Figure 17: Effect of applied magnetic fields on the measured and predicted effective anode voltage, $J_{\text {arc }}=6 \mathrm{~A}$. 


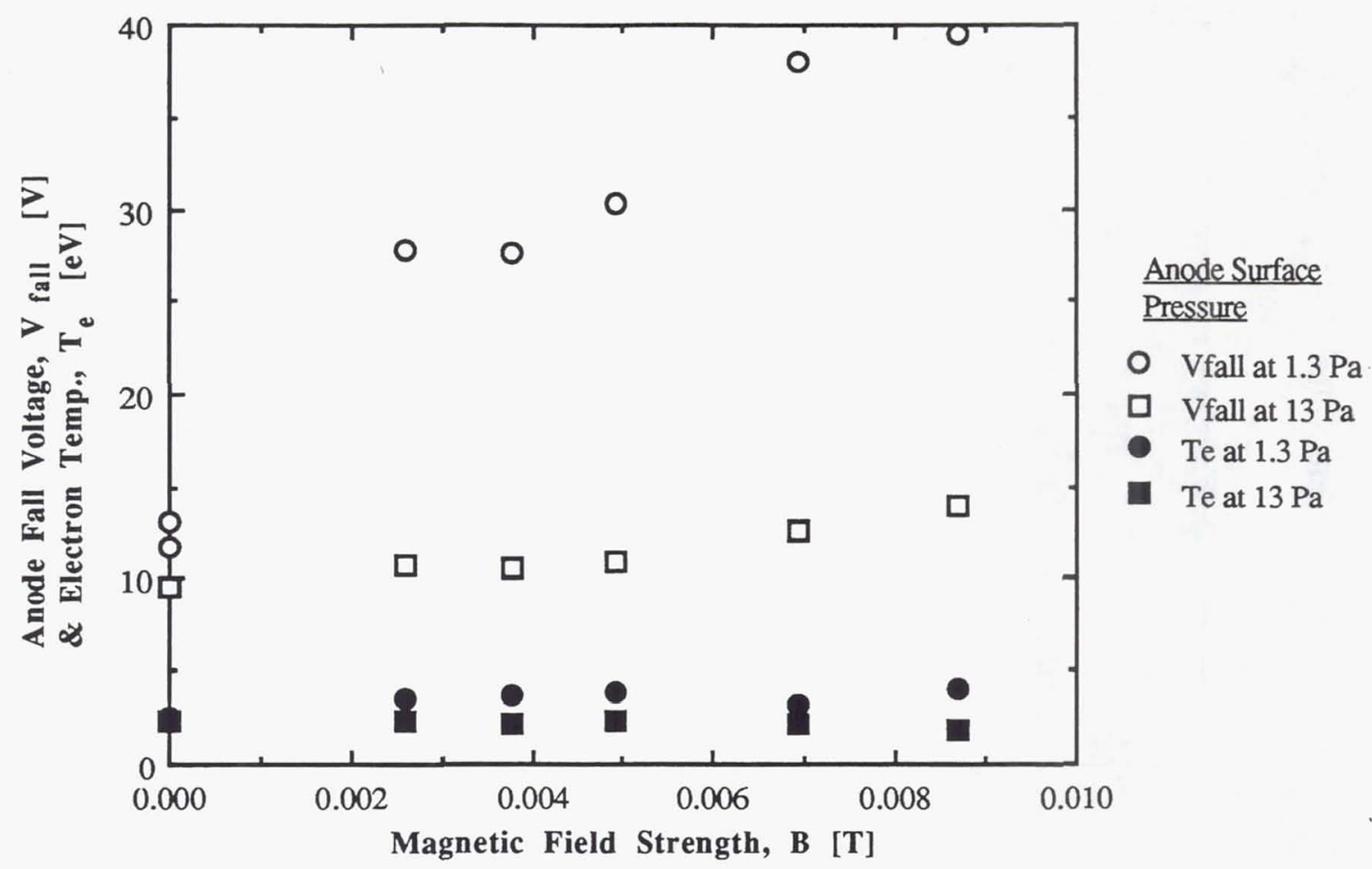

Figure 18: Effect of applied magnetic fields on the anode fall voltage and electron temperature, $J_{\text {arc }}=6 \mathrm{~A}$.

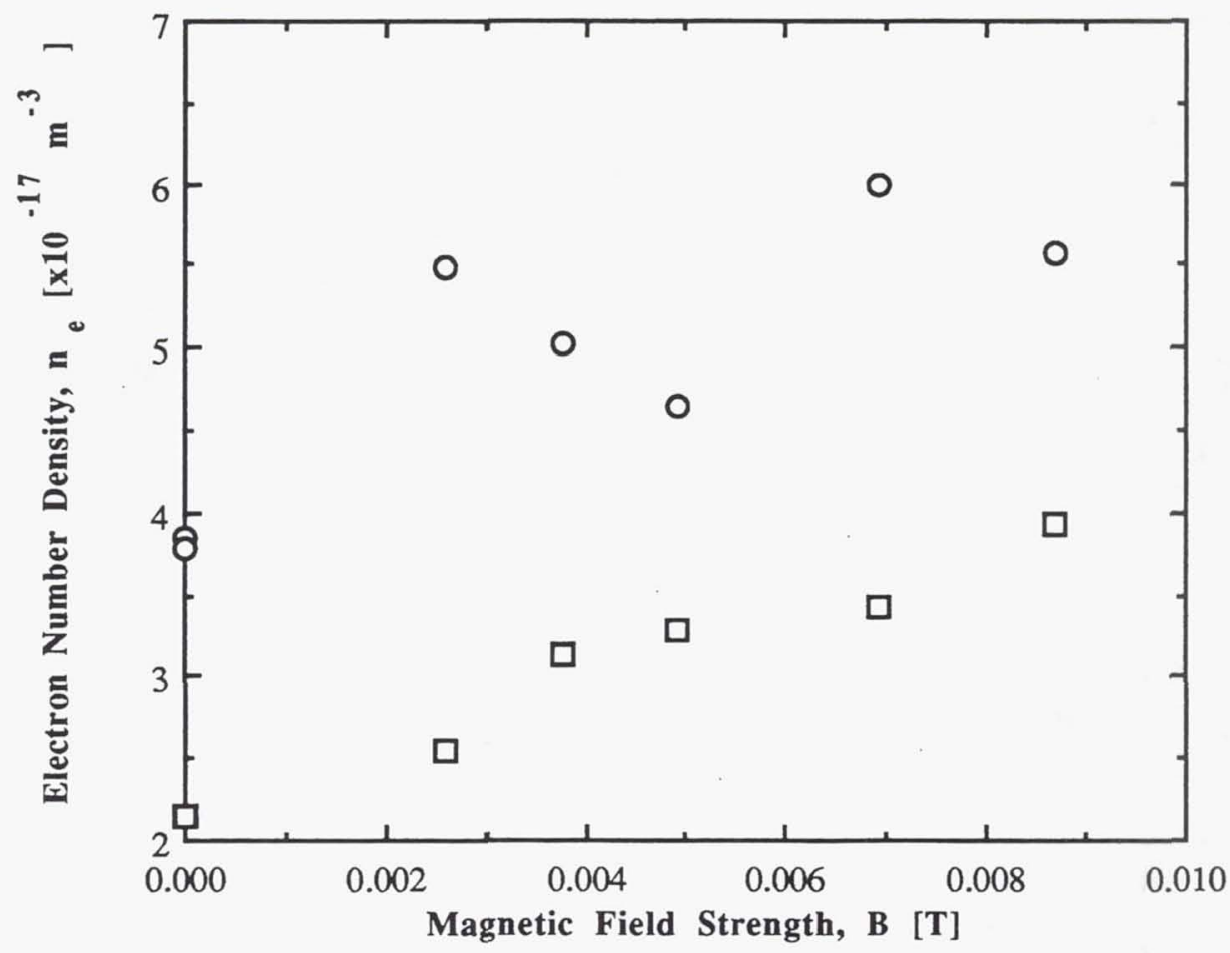

Anode Surface

Pressure

- $1.3 \mathrm{~Pa}$

$13 \mathrm{~Pa}$

Figure 19: Effect of applied magnetic fields on the electron number density, $\mathrm{J}_{\text {arc }}=6 \mathrm{~A}$. 


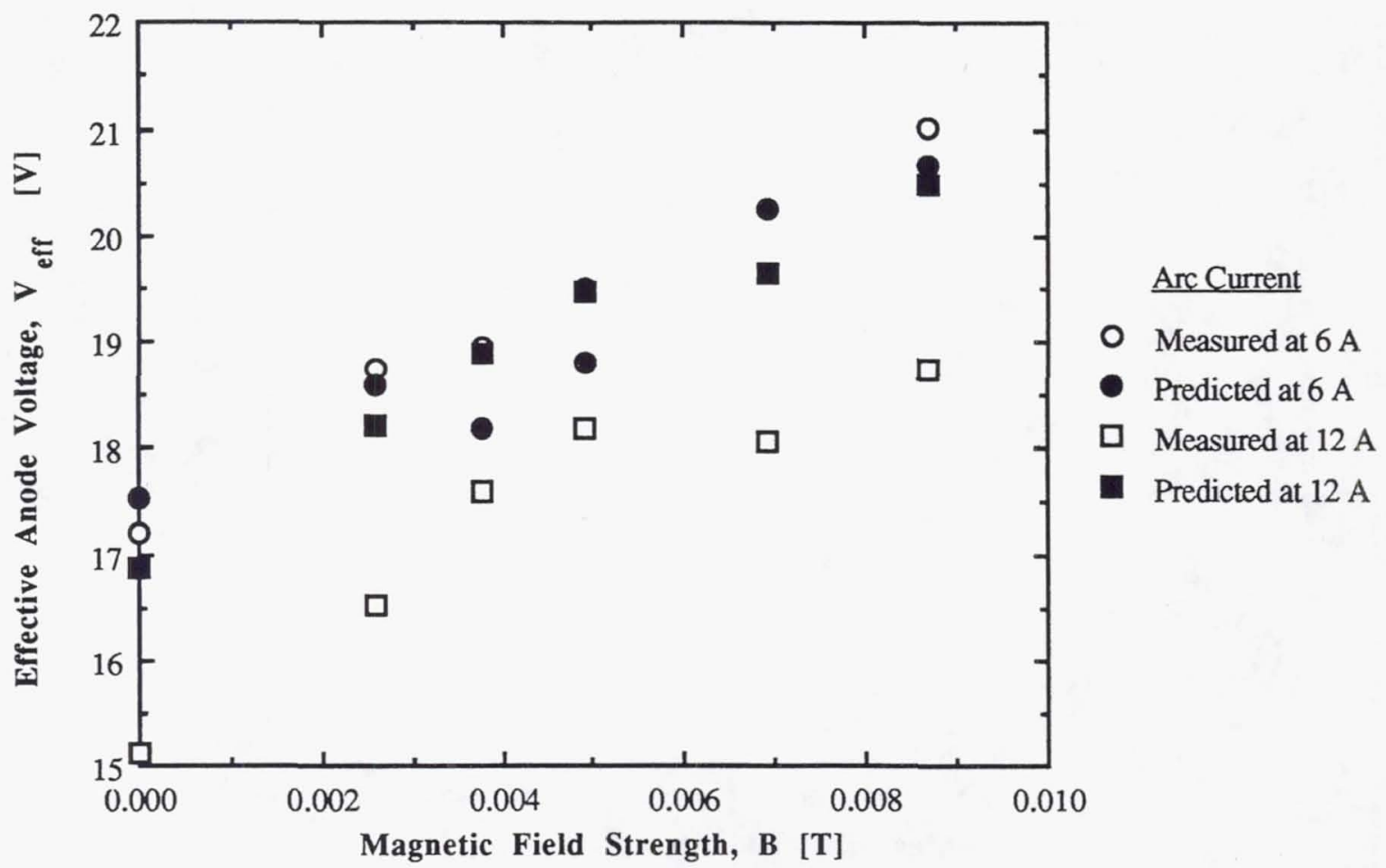

Figure 20: Effect of applied magnetic fields on the measured and predicted effective anode voltage, $p=13 \mathrm{~Pa}$.

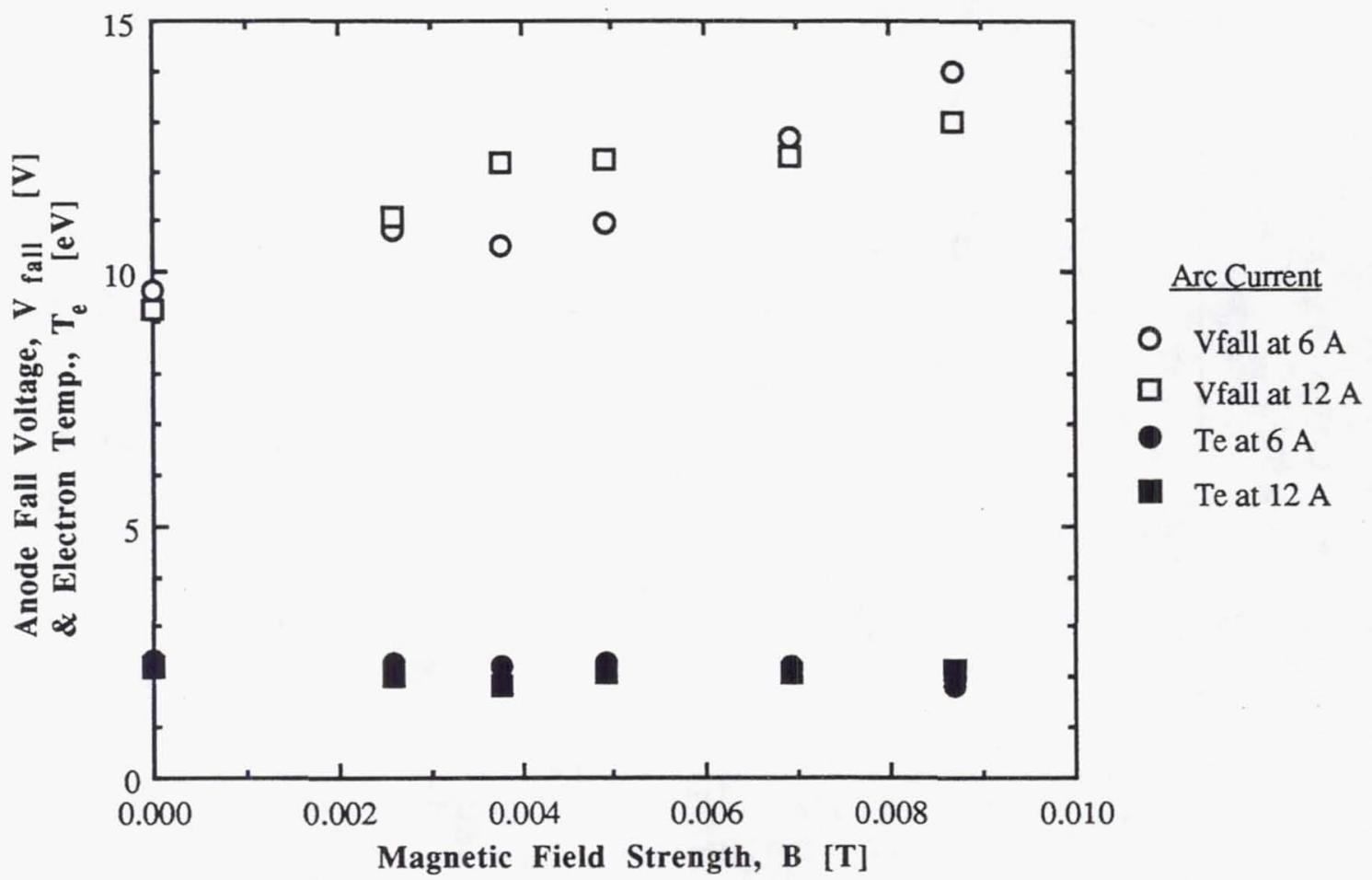

Figure 21: Effect of applied magnetic fields on the anode fall voltage and electron temperature, $p=13 \mathrm{~Pa}$. 


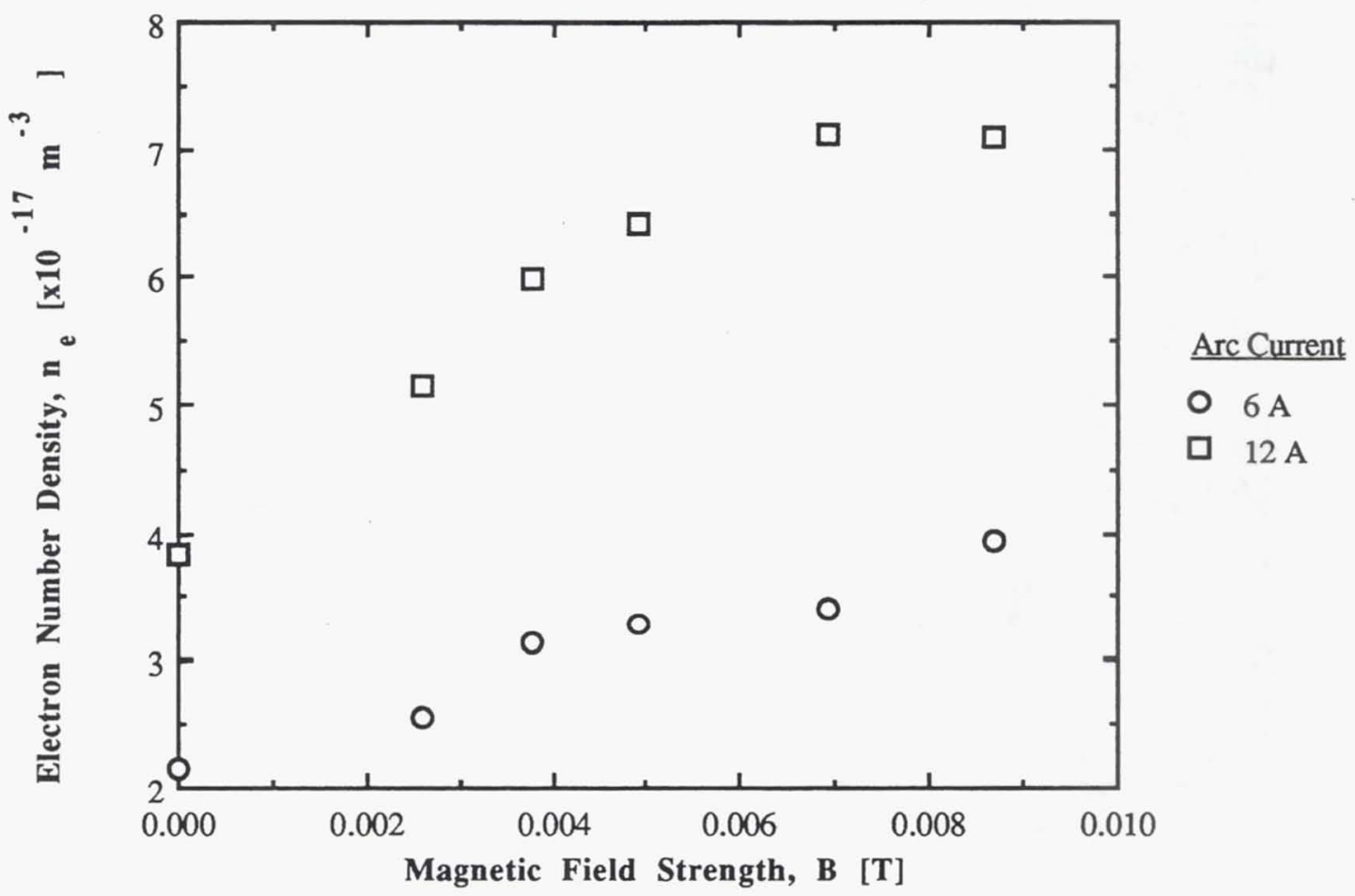

Figure 22: Effect of applied magnetic fields on the electron number density, $p=13 \mathrm{~Pa}$.

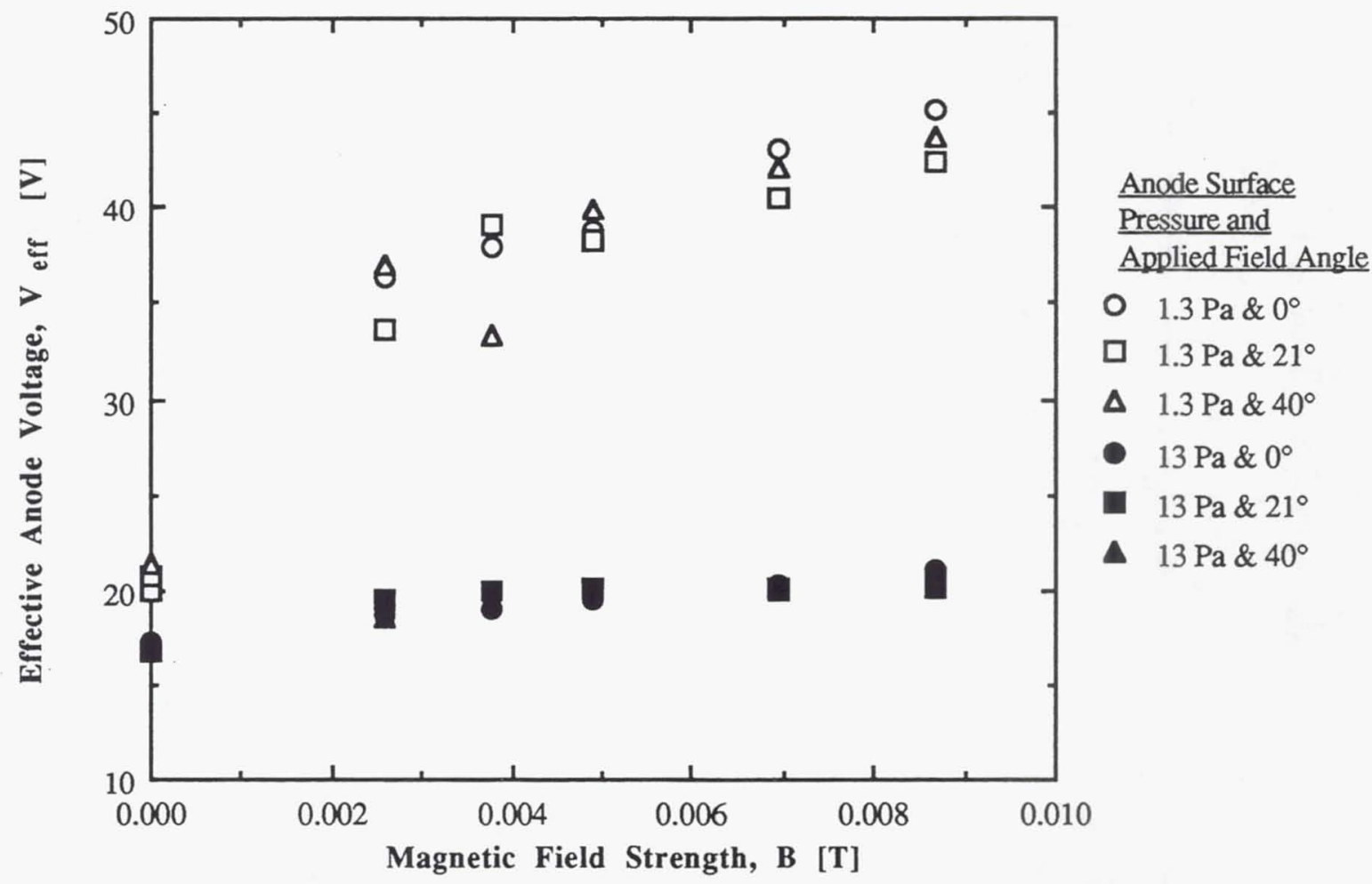

Figure 23: Effect of applied magnetic fields on the effective anode voltage, $\mathrm{J}_{\text {arc }}=6 \mathrm{~A}$. 


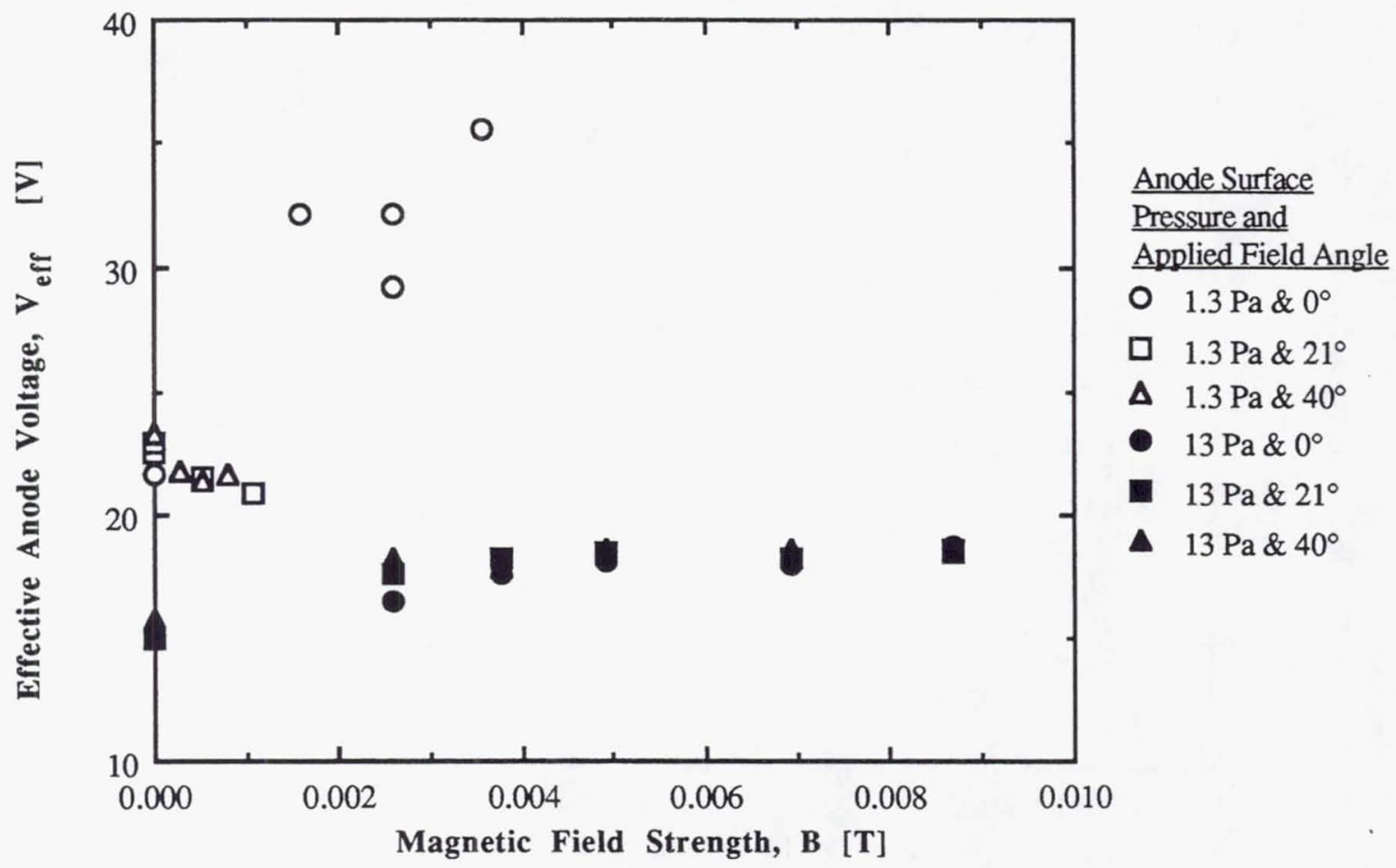

Figure 24: Effects of applied magnetic fields on the effective anode voltage, $J_{\text {arc }}=12 \mathrm{~A}$.

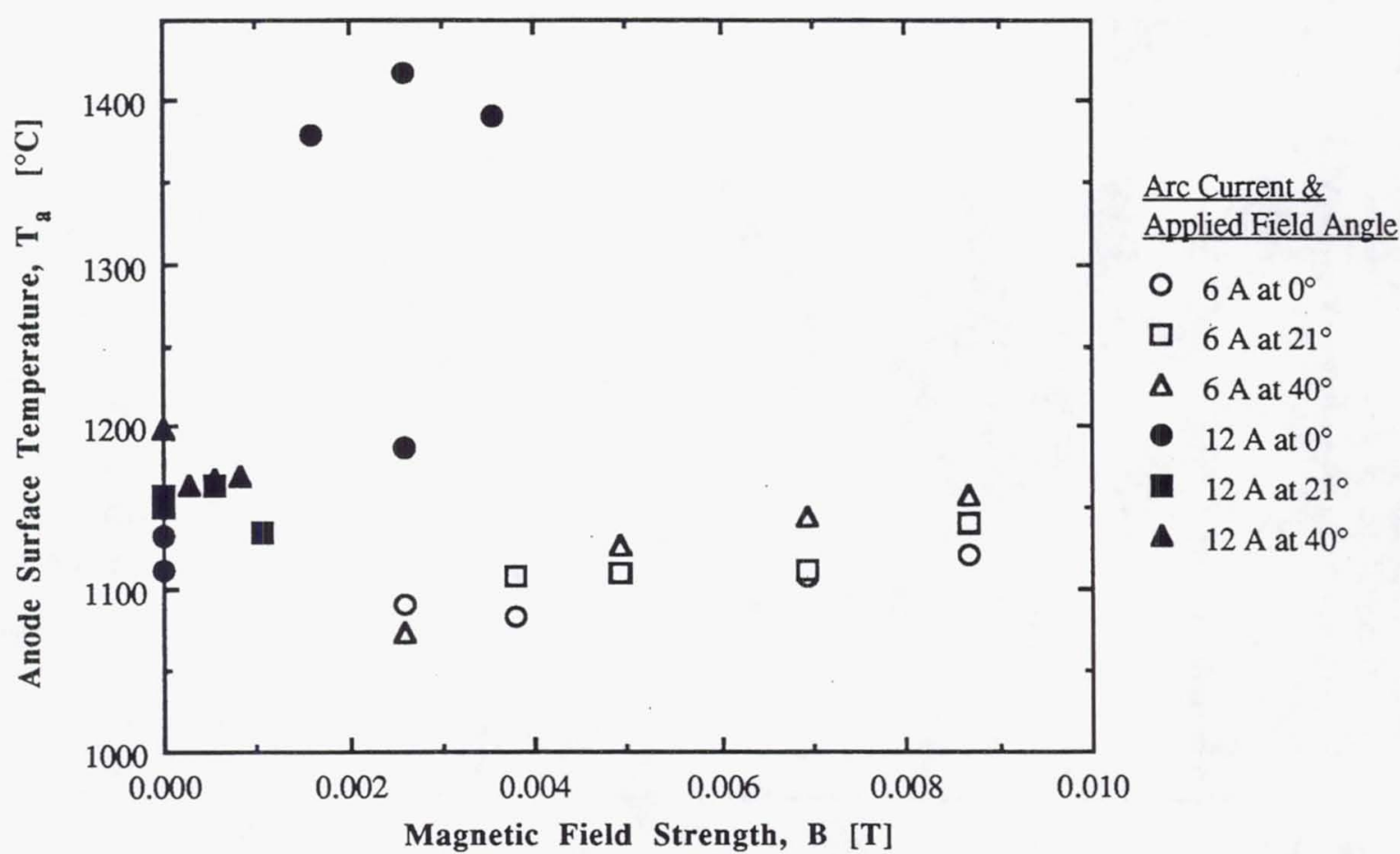

Figure 25: Effect of applied magnetic fields on the anode surface temperature, $\mathrm{p}=1.3 \mathrm{~Pa}$. 


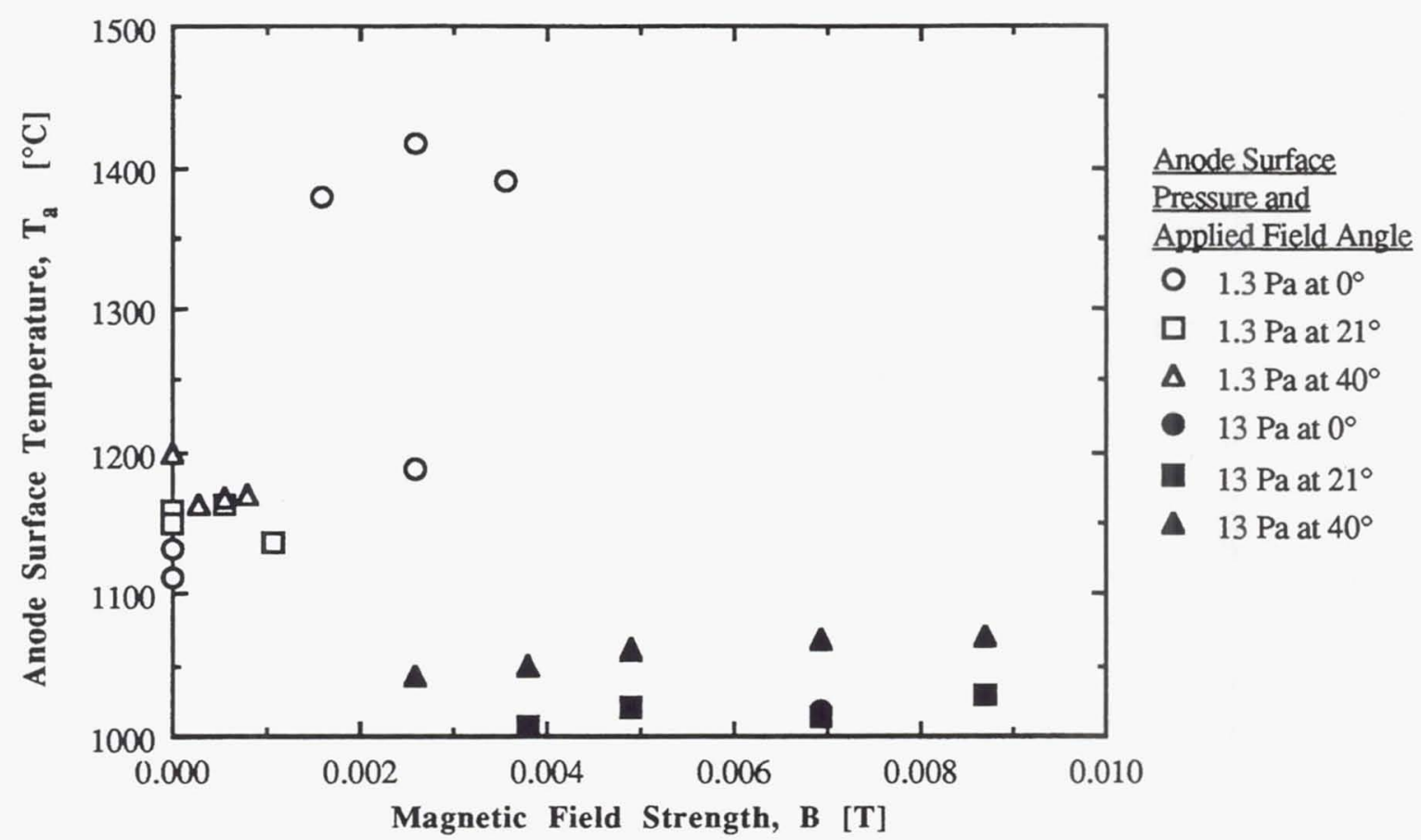

Figure 26: Effect of applied magnetic fields on the anode surface temperature, $J_{\text {arc }}=12 \mathrm{~A}$.

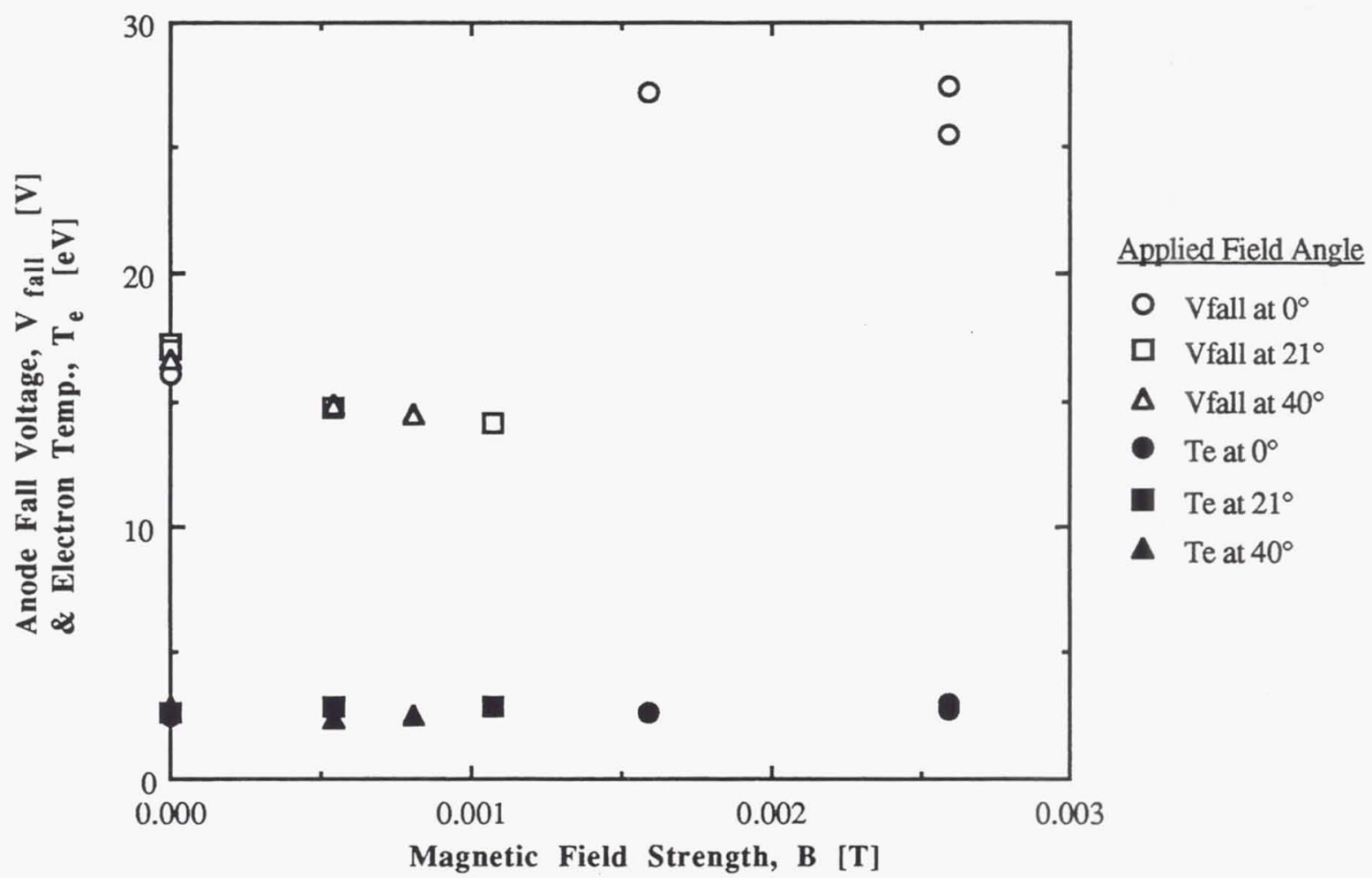

Figure 27: Effect of applied magnetic fields on the anode fall voltage and the electron temperature, $p=1.3 \mathrm{~Pa}, \mathrm{~J}_{\text {arc }}=12 \mathrm{~A}$. 


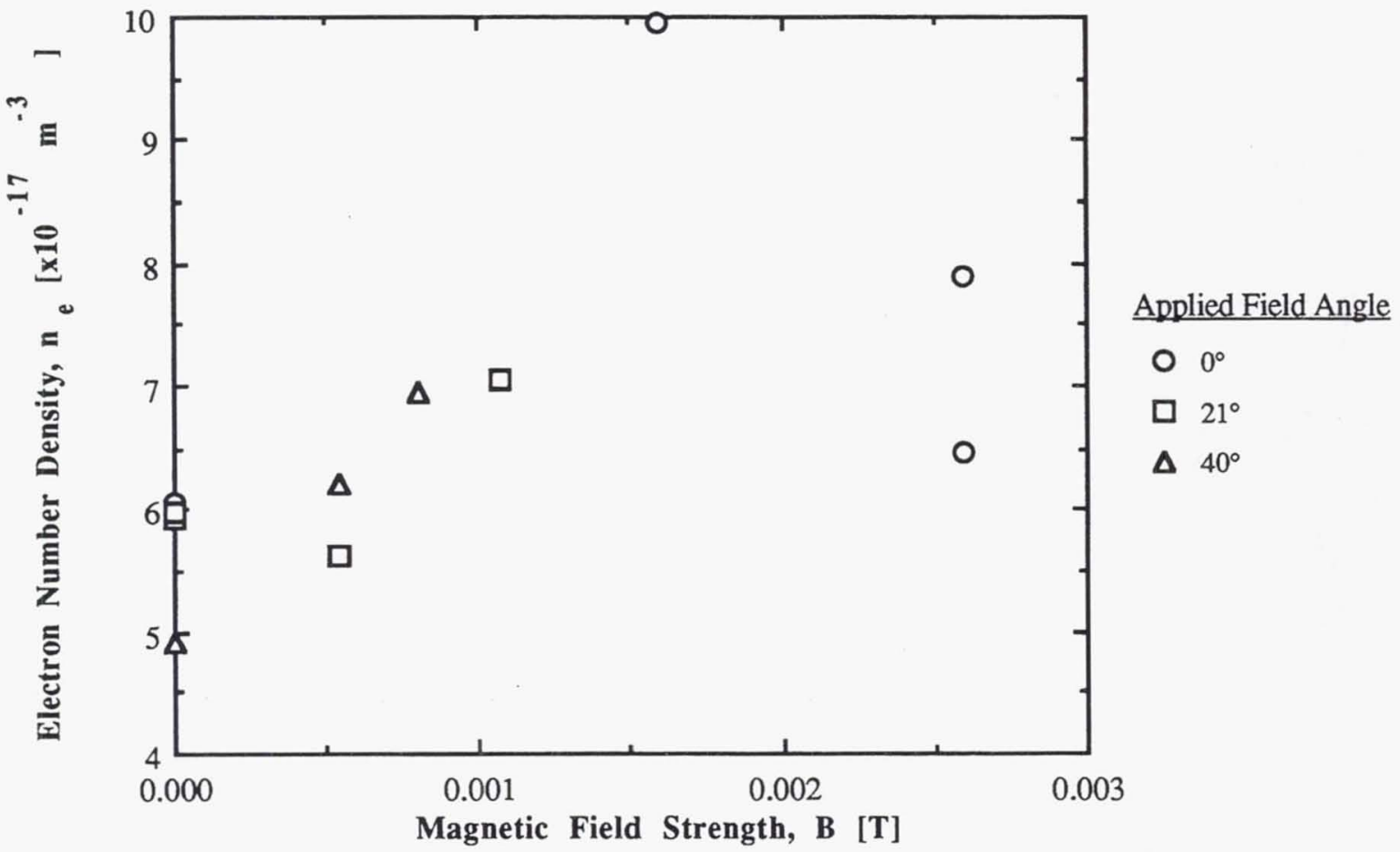

Figure 28: Effect of applied magnetic fields on the electron number density, $\mathrm{p}=1.3 \mathrm{~Pa}, \mathrm{~J}_{\text {arc }}=12 \mathrm{~A}$. 
Public reporting burden for this collection of information is estimated to average 1 hour per response, including the time for reviewing instructions, searching existing data sources, gathering and maintaining the data needed, and completing and reviewing the collection of information. Send comments regarding this burden estimate or any other aspect of this collection of information, including suggestions for reducing this burden, to Washington Headquarters Services, Directorate for Information 'Operations and Reports, 1215 Jefferson Davis Highway, Suite 1204, Arlington, VA 22202-4302, and to the Office of Management and Budget, Paperwork Reduction Project (0704-0188), Washington, DC 20503.

\begin{tabular}{|l|l|r|}
\hline 1. AGENCY USE ONLY (Leave blank) & $\begin{array}{c}\text { 2. REPORT DATE } \\
\text { January } 1994\end{array}$ & $\begin{array}{r}\text { 3. REPORT TYPE AND DATES COVERED } \\
\text { Final Contractor Report }\end{array}$
\end{tabular}

\section{TITLE AND SUBTITLE}

Mechanisms of Anode Power Deposition in a Low Pressure Free Burning Arc

6. AUTHOR(S)

George C. Soulas and Roger M. Myers
5. FUNDING NUMBERS

WU-506-42-31

C-NAS3-25266

8. PERFORMING ORGANIZATION REPORT NUMBER

Ohio State University

Columbus, Ohio 43210

E-8303

\section{SPONSORING/MONITORING AGENCY NAME(S) AND ADDRESS(ES)}

National Aeronautics and Space Administration

Lewis Research Center

Cleveland, Ohio 44135-3191

\section{SPONSORING/MONITORING} AGENCY REPORT NUMBER

NASA CR-194442

IEPC-93-194

11. SUPPLEMENTARY NOTES

Prepared for the 23rd International Electric Propulsion Conference cosponsored by AIAA, AIDAA, DGLR, and JSASS, Seattle, Washington, September 13-16, 1993. George C. Soulas, Ohio State University; and Roger M. Myers, Sverdrup Technology, Inc., Lewis Research Center Group, 2001 Aerospace Parkway, Brook Park, Ohio 44142. Project Manager, James S. Sovey, Space Propulsion Technology Division, (216) 433-7454.

12a. DISTRIBUTIONAVAILABILITY STATEMENT

12b. DISTRIBUTION CODE

Unclassified - Unlimited

Subject Category 75

\section{ABSTRACT (Maximum 200 words)}

Anode power deposition is a dominant power loss mechanism for arcjets and MPD thrusters. In this study, a free burning arc experiment was operated at pressures and current densities similar to those in arcjets and MPD thrusters in an attempt to identify the physics controlling this loss mechanism. Use of a free burning arc allowed for the isolation of independent variables controlling anode power deposition and provided a convenient and flexible way to cover a broad range of currents, anode surface pressures, and applied magnetic field strengths and orientations using an argon gas. Test results showed that anode power deposition decreased with increasing anode surface pressure up to $6.7 \mathrm{~Pa}$ ( 0.05 torr) and then became insensitive to pressure. Anode power increased with increasing arc current while the electron number density near the anode surface increased linearity. Anode power also increased with increasing applied magnetic field strength due to an increasing anode fall voltage. Applied magnetic field orientation had an effect only at high currents and low anode surface pressures, where anode power decreased when applied field lines intercepted the anode surface. The results demonstrated that anode power deposition was dominated by the currentcarrying electrons and that the anode fall voltage was the largest contributor. Furthermore, the results showed that anode power deposition can be reduced by operating at increased anode pressures, reduced arc currents and applied magnetic field strengths, and with magnetic field lines intercepting the anode.

\begin{tabular}{|c|c|c|}
\hline \multicolumn{3}{|l|}{ 14. SUBJECT TERMS } \\
\hline $\begin{array}{l}\text { 17. SECURITY CLASSIFICATION } \\
\text { OF REPORT } \\
\text { Unclassified }\end{array}$ & $\begin{array}{l}\text { 18. SECURITY CLASSIFICATION } \\
\text { OF THIS PAGE } \\
\text { Unclassified }\end{array}$ & $\begin{array}{l}\text { 19. SECURITY CLASSIFICATION } \\
\text { OF ABSTRACT } \\
\text { Unclassified }\end{array}$ \\
\hline & & \\
\hline
\end{tabular}




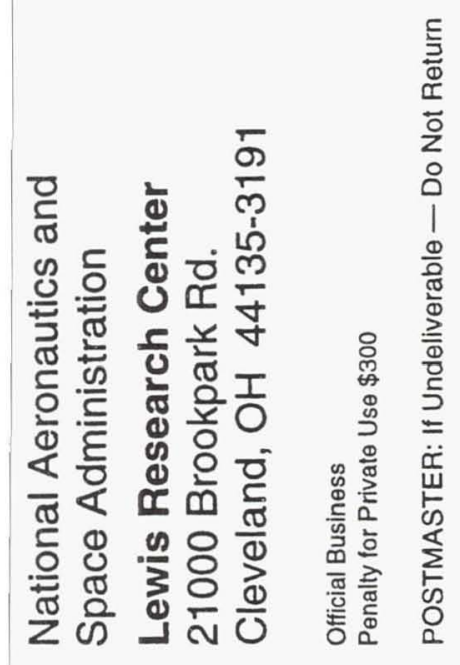

